\title{
The Colletotrichum acutatum Gene Encoding a Putative pH-Responsive Transcription Regulator Is a Key Virulence Determinant During Fungal Pathogenesis on Citrus
}

\author{
Bang-Jau You, Mathias Choquer, and Kuang-Ren Chung \\ Citrus Research and Education Center and Department of Plant Pathology, Institute of Food and Agricultural Sciences \\ (IFAS), University of Florida, 700 Experiment Station Road, Lake Alfred, FL 33850, U.S.A.
}

Submitted 28 February 2007. Accepted 18 April 2007.

Postbloom fruit drop of citrus and Key lime anthracnose (KLA) are caused by different pathotypes of Colletotrichum acutatum. Both pathotypes are pathogenic to citrus flowers, resulting in blossom blight and induction of young fruit abscission. Two fungal mutants defective in pathogenicity were recovered from a KLA pathotype after Agrobacterium-mediated mutagenesis. A $\mathrm{PacC}^{\mathrm{KLAP2}}$ gene encoding a polypeptide that resembles many $\mathrm{pH}$-responsive $\mathrm{PacC} /$ Rim101 transcription regulators in fungi was identified from one of the mutants, and functionally characterized to play a crucial role in pathogenesis to both Key lime leaves and citrus flowers. Gene disruption at the PacC ${ }^{K L A P 2}$ locus created fungal mutants that were hypersensitive to alkaline pH, altered in conidium and appressorium production and germination, and concomitant with reduced virulence to both tissues. The pac $C^{\text {klap2 }}$ null mutants had lower alkaline phosphatase and protease activities, but increased pectolytic and lipolytic activities. The mutants initiated penetration and incited lesion formation on Key lime, indistinguishable from the wild type, when a functional copy of PacC ${ }^{K L A P 2}$ was reintroduced or the leaves were wounded prior to inoculation. The null mutants were blocked at the penetration stage and, thus, failed to initiate the necrotrophic phase. The PacC ${ }^{K L A P 2}$ transcript was barely detectable when the fungus was grown on medium buffered to $\mathrm{pH} 3$ or 4, yet accumulated to high levels at a pH between 5 and 7. The PacC $C^{K L A P 2}$ transcript was detected 2 days postinoculation on Key lime leaves, correlating with the time of lesion formation. We conclude that $\mathrm{PacC}^{\mathrm{KLAP2}}$ is essential for $C$. acutatum pathogenesis by regulating multiple physiological and developmental processes.

Additional keywords: Agrobacterium-mediated transformation, sweet orange, targeted gene disruption, transcription factors, zinc finger.

Corresponding author: K.-R. Chung; Telephone: 863 956-1151 ext. 1369; Fax: 863 956-4631; E-mail: krchung@ufl.edu

The $P a c C^{K L A P 2}$ gene sequence is available in the GenBank and EMBL databases under accession number EF137939.

* The $\boldsymbol{e}$-Xtra logo stands for "electronic extra" and indicates that Figures 5,6 , and 7 appear in color online. A supplementary figure also appears online.
Fungal species in the genus Colletotrichum are ubiquitous in nature, and many cause diseases of a wide range of plants. On citrus, Colletotrichum acutatum has two distinct pathotypes. The Key lime anthracnose (KLA) pathotype causes anthracnose on most organs of Key lime: leaves, flowers, and fruit (Agostini et al. 1992). The postbloom fruit drop (PFD) pathotype infects only flower petals and causes blossom blight, inducing young fruit abscission of most citrus species and resulting in severe yield losses. PFD is a severe problem and has become a limiting factor for citrus production in Central and South America, where the climates are humid (Timmer et al. 1994). In Florida, yield losses due to PFD have been observed in some years when rainfall was high during flowering in spring. The PFD pathotype survives by forming melanized appressoria that reside as a quiescent stage on vegetative tissues in the absence of flower petals (Timmer et al. 1994). The PFD pathotype does not colonize and penetrate vegetative tissues during the quiescent stage (Peres et al. 2005). Under favorable conditions, appressoria are readily induced by flower extracts to germinate and produce hyphae and a few conidia which are splashed onto flowers to begin a new disease cycle (Timmer et al. 1994). The PFD pathotype reproduces only on flower petals, and forms acervuli with massive numbers of conidia that are disseminated from flower to flower. Due to premature fruit abscission, PFD needs to be controlled. However, fungicide application for PFD often is inadequate, mainly because fungicides only prevent further spread of the disease, but fail to stop young fruit drop.

In contrast, the KLA pathotype infects most organs of Key lime, resulting in anthracnose on leaves, twigs, and flowers. The KLA pathotype also induces young fruit abscission and calyx enlargement on Key lime, as does the PFD pathotype (Chen et al. 2005; Timmer et al. 1994). In addition, the KLA pathotype is able to infect flowers of sweet orange, resulting in young fruit drop. It has been speculated that the PFD pathotype originated from the KLA pathotype. Comparisons of the sequences of the internal transcribed spacer and other conserved regions indicate that they are no more closely related than isolates from noncitrus hosts (Peres et al. 2005).

Young fruit abscission induced by $C$. acutatum has been attributed to the imbalance of the intracellular levels of plant hormones and growth regulators (Chen et al. 2006; Chung et al. 2003a; Lahey et al. 2004; Li et al. 2003). In this laboratory, much effort has focused on determination of common or unique factors that are required for pathogenicity or virulence in KLA and PFD isolates (Chen et al. 2005). To gain more in- 
sight into our understanding the interactions between $C$. $a c u$ tatum and citrus from molecular aspects, a genetic transformation tool for manipulation of $C$. acutatum isolates was developed (Chung et al. 2002). This transformation system, along with the restriction enzyme-mediated integration (REMI) mutagenesis (Kuspa and Loomis 1992), then was used to screen for nonpathogenic mutants after transforming a plasmid with various endonucleases into a KLA isolate. As such, a Key lime anthracnose pathogenicity gene (KLAPl) encoding a novel $\mathrm{C}_{2} \mathrm{H}_{2}$ transcription factor was identified from one of the REMI-generated mutants and has been shown to be essential for pathogenicity of $C$. acutatum to Key lime leaves but not to flower petals (Chen et al. 2005).

In the present study, we utilized an Agrobacterium-mediated integration mutagenesis (Mullins et al. 2001) approach to identify two fungal mutants defective in lesion formation on detached Key lime leaves after screening hundreds of independent transformants of a KLA isolate. A gene displaying strong amino acid similarity to numerous $\mathrm{pH}$-responsive $\mathrm{PacC}$ transcription regulators of fungi was identified from one of the mutants. The environmental $\mathrm{pH}$ is one of the most important signal cues that are involved in physiological functions and developmental processes in all organisms. Many fungal responses to ambient $\mathrm{pH}$ signaling are dependent upon conserved $\mathrm{PacC} /$ Rim101 transcription regulators, which activate or suppress expression of numerous genes involved in growths, developmental differentiations, and the production of secreted enzymes, permeases, and secondary metabolites (Arst and Peñalva 2003; Espeso et al. 1993; Peñalva and Arst 2002, 2004). Here, we report the function of gene $P a c C^{K L A P 2}$ that is required for fungal penetration and lesion formation on Key lime leaves and citrus flowers during pathogenesis of $C$. acutatum by molecular and genetic analyses.

\section{RESULTS}

Identification of fungal mutants defective in pathogenicity.

Over 800 transformants of $C$. acutatum were recovered from media containing hygromycin after Agrobacterium-mediated transformation in two independent experiments. Fungal pathogenicity was evaluated first on detached Key lime leaves using agar plugs with fungal cultures grown on potato dextrose agar (PDA). Two transformants (T42 and T240) that incited mild necrotic lesions on Key lime leaves were selected for further characterization. Inoculations using conidial suspension of two such transformants validated their phenotype of reduced pathogenicity. Southern blot analysis with an $H Y G$ probe was used

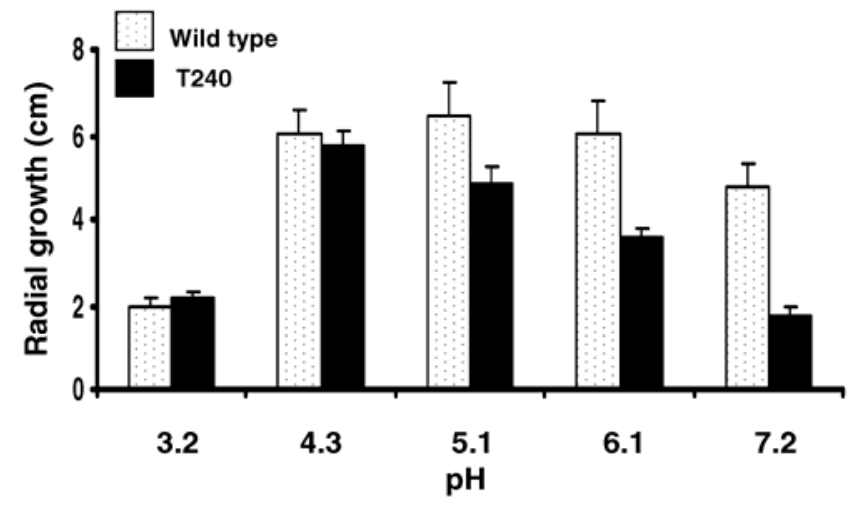

Fig. 1. Growth of Colletotrichum acutatum wild type and T240 isolate on potato dextrose agar with various $\mathrm{pH}$ values as indicated. Fungal growth was measured in diameters at 6 days postinoculation. Each column represents the means of colony diameter \pm the standard deviation from two independent experiments with at least three replicates. to determine the copy numbers of the integrated T-DNA in T42 and T240 and revealed a single insertion of $H Y G$ in both transformants (data not shown).

\section{Cloning of the PacC $\mathrm{CLAP2}^{\mathrm{Kene} .}$}

A thermal asymmetric interlaced polymerase chain reaction (TAIL-PCR) protocol was carried out to recover DNA fragments flanking the T-DNA integration site. No DNA was obtained from T42 after several attempts, and this transformant was not further characterized. In contrast, a $0.9-\mathrm{kb}$ fragment was amplified from genomic DNA of T240 and was cloned to become pKLA240 for sequence analysis. Database searches (Blastx) revealed that the rescued sequence has strong amino acid similarity to many $\mathrm{pH}$-response $\mathrm{PacC} / \mathrm{Rim} 101$ transcription factors of fungi and yeasts (Supplementary Fig. 1). The C. acutatum gene presumably required for pathogenesis toward Key lime was named the $P a c C^{K L A P 2}$ gene. Sequence analysis revealed that T-DNA was integrated in the promoter region $56 \mathrm{bp}$ upstream from the predicted ATG translational initiation codon of $P a c C^{K L A P 2}$ in T240. Phenotypic assays on radial growth indicated that T240 was hypersensitive to neutral and alkaline $\mathrm{pH}$, because its growth was severely reduced on media with $\mathrm{pH}$ values higher than 6 (Fig. 1).

A chromosomal library of $C$. acutatum was constructed and used to clone the $P a c C^{K L A P 2}$ gene. Two DNA fragments overlapping with the rescued $0.9-\mathrm{kb}$ fragment on either side were amplified and sequenced. In total, 2,866 bp sequences encompassing the entire $P a c C^{K L A P 2}$ coding region as well as its upstream promoter and downstream nontranslated regions were assembled. Analysis of the combined sequences derived from genomic clones and the cDNA revealed that $P a c C^{K L A P 2}$ contains a 1,770-bp open reading frame (ORF) with three introns of 67, 61 , and $77 \mathrm{bp}$ in lengths. Southern blot hybridization of the $C$. acutatum genomic DNA digested with different restriction enzymes (EcoRV, NotI, NruI, PvuII, SacII, or XhoI), whose target sequences are not present within $P a c C^{K L A P 2}$, implied a single copy of $P a c C^{K L A P 2}$ in the C. acutatum genome (data not shown). Analysis of the 849 nucleotides upstream from the putative ATG start codon of $P a c C^{K L A P 2}$ identified five copies of the putative PacC consensus binding sequence (5'-GCCARG3') of Aspergillus (also known as Emericella) nidulans (Arst and Peñalva 2003; Espeso et al. 1993; Peñalva and Arst 2002, 2004; Tilburn et al. 1995).

\section{Identification of consensus domains in PacC ${ }^{\mathrm{KLAP2}}$.}

Conceptual translation indicated that the Pac $C^{K L A P 2}$ ORF encodes a polypeptide of 590 amino acids. The $P a c C^{K L A P 2}$ translational product has considerable amino acid identities (43 to $65 \%$ ) and similarities (55 to $74 \%$ ) to a number of PacC orthologs identified in Gibberella moniformis (accession number AAO64251), G. fujikuroi (CAD55803), Fusarium oxysporum (AAM95700), Acremonium chrysogenum (CAC38840), Magnaporthe grisea (Q52B93), Neurospora crassa (Q7RVQ8), Sclerotinia sclerotiorum (AAF93178), Botryotinia fuckeliana (AAV54519), and many Aspergillus spp. (CAA67063, BAB20756, AAV28549, AAK98616, and EAU35187). The strongest similarity was detected in the zinc-finger regions.

A ScanProsite analysis identified three distinct $\mathrm{Cys}_{2} \mathrm{His}_{2-}$ type zinc finger motifs (residues 42 to 67,78 to 102 , and 108 to 130) (Fig. 2) that are found commonly in the transcription factors of filamentous fungi. All three motifs have the consensus residues $\mathrm{C}\left(\mathrm{X}_{2-4}\right) \mathrm{C}\left(\mathrm{X}_{12}\right) \mathrm{H}\left(\mathrm{X}_{3-5}\right) \mathrm{H}$. Several conserved regions (I to VII) that commonly are present in PacC transcription factors of fungi (Díez et al. 2002; Espeso et al. 1997; Tilburn et al. 1995; Vincent et al. 2003) also were found in PacC ${ }^{\mathrm{KLAP2}}$. Analysis using Motif/ProDom and Block programs identified a putative region involved in transcription activation (region I; 
within residues 182 to 192), a putative bipartite nuclear localization signal and a proteolytic processing site (region II; within residues 218 to 237), and at least four putative DNAbinding sites (residues 35 to 71, 123 to 159, 227 to 263, and 528 to 564) in $\mathrm{PacC}^{\mathrm{KLAP} 2}$ (Fig. 2). Region III is glycine rich, whereas region IV is rich in glutamine residues. A putative $\mathrm{Na}^{+} / \mathrm{HCO}_{3}$-cotransporter signature (residues 380 to 387; region $\mathrm{V})$ has serine- and proline-rich residues. A putative signaling protease box was identified within residues 456 to 468 (region VI). The central region of $\mathrm{PacC}^{\mathrm{KLAP} 2}$ also is highly rich in tyrosine and glutamine residues. In addition, PacC ${ }^{\mathrm{KLAP} 2}$ is very rich in the S/TPxx residues, having 5 TPxx and 15 SPxx motifs particularly abundant in the $\mathrm{C}$ terminus. The $\mathrm{C}$ terminus of $\mathrm{PacC}^{\mathrm{KLAP} 2}$ is very alanine- and arginine-rich, with 17 alanines and 14 arginines in the last 120 amino acids (region VII). Two PalA-binding sites were identified in the $\mathrm{C}$ terminus of $\mathrm{PacC}^{\mathrm{KLAP} 2}$. Those conserved sequences also have been described in the Aspergillus nidulans PacC (Vincent et al. 2003).

\section{Functional characterizations of $\mathrm{PacC}^{\mathrm{KLAP2}}$.}

Targeted gene disruption specifically within $P a c C^{K L A P 2}$ was performed to determine the biological functions of the $P_{a c C^{K L A P 2}}$ gene in C. acutatum (Fig. 3A). PCR fragments that were amplified from a disruption construct were mixed and directly transformed into the wild-type strain (KLA207). Transformants first were recovered from a medium amended with sulfonylurea and screened for $P a c C^{K L A P 2}$ disruption by growing them on PDA buffered at $\mathrm{pH} 7$. In total, 6 of 171 transformants (4\%) displayed a marked growth reduction on medium of $\mathrm{pH} 7$ and were selected as putative Pac $C^{K L A P 2}$ disruptants for further characterization. Southern blot analysis showing different hybridization patterns between the wild type and transformants confirmed successful disruption in the PacC $C^{K L A P 2}$ locus (Fig. 3). As a result, the $S U R$ cassette was integrated in the middle of $P_{a c} C^{K L A P 2}$ (between 894 and 945 nucleotides downstream from the ATG initiation codon). Genomic DNA from the wild-type strain and five transformants was hybridized to a $P a c C^{K L A P 2}$ probe and resulted in the expected $1.2-\mathrm{kb}$ NheI hybridizing band from the wild-type DNA. However, a 1.4-kb band was identified in DNA of five transformants as a consequence of the integration of $S U R$, and the presence of an extra NheI endonuclease site in the $S U R$ cassette. In addition to the 1.4-kb band, small hybridizing bands $(<1 \mathrm{~kb})$ were detected in DNA from D2 and D5 transformants (Fig. 3B) which likely were the result of ectopic integration of the split marker fragments. Northern

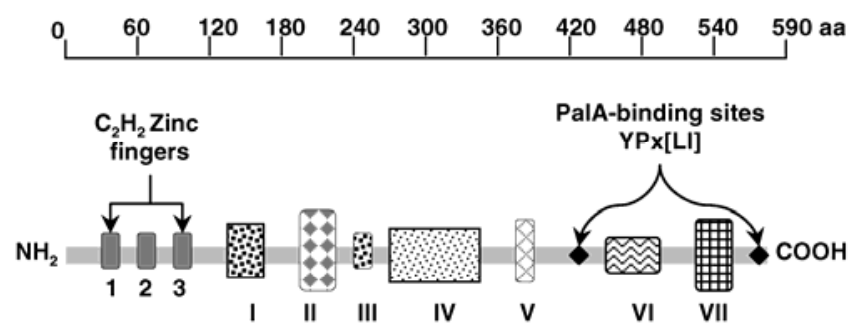

Region I: Transcription activation

Region II: Nuclear localization; processing protease

Region III: Glycine-rich

Region IV: Glutamine-rich

Region V: Proline and serine-rich; $\mathrm{Na}+/ \mathrm{HCO}_{3}$-cotransporter signature

Region VI; Signal protease box

Region VII: Alanine/Arginine/Glutamine-rich

Fig. 2. Schematic depiction of the Colletotrichum acutatum PacC $\mathrm{KLAP}^{2}$ protein showing conserved PacC-like domains and signatures which are potentially important for protein configurations and functions. PacC ${ }^{\mathrm{KLAP} 2}$ contains three sets of zinc finger $\left(\mathrm{Cys}_{2} \mathrm{His}_{2}\right)$ domains. The relative size of amino acids of $\mathrm{PacC}^{\mathrm{KLAP} 2}$ also is shown. blot hybridization of total RNA to a $P a c C^{K L A P 2}$-specific probe identified a 2.3-kb transcript in total RNA of the wild type but failed to detect any transcript in three transformants (Fig. 3C), indicating that they were pac $C^{k l a p 2}$ null mutants.

Genetic complementation was conducted by reintroducing a functional Pac $C^{K L A P 2}$ gene cassette with the plasmid pUCATPH harboring a hygromycin phosphotransferase B gene into the D3 null mutant. Genetically reverted strains first were identified on a medium containing hygromycin and tested for growth restoration on alkaline PDA $(\mathrm{pH} 8)$. In all, 5 of 28 transformants exhibited radial growth comparable with that of the wild type on alkaline PDA. Northern blot analysis of fungal RNA from one transformant revealed that the $\mathrm{PacC}^{K L A P 2}$-complemented strain accumulated higher levels of $\mathrm{PaCC}^{K L A P 2}$ transcript than the wild type (Fig. 3C). Small transcripts, likely representing truncated or splicing variants of $P a c C^{K L A P 2}$, also were identified in RNA from the complemented strain.
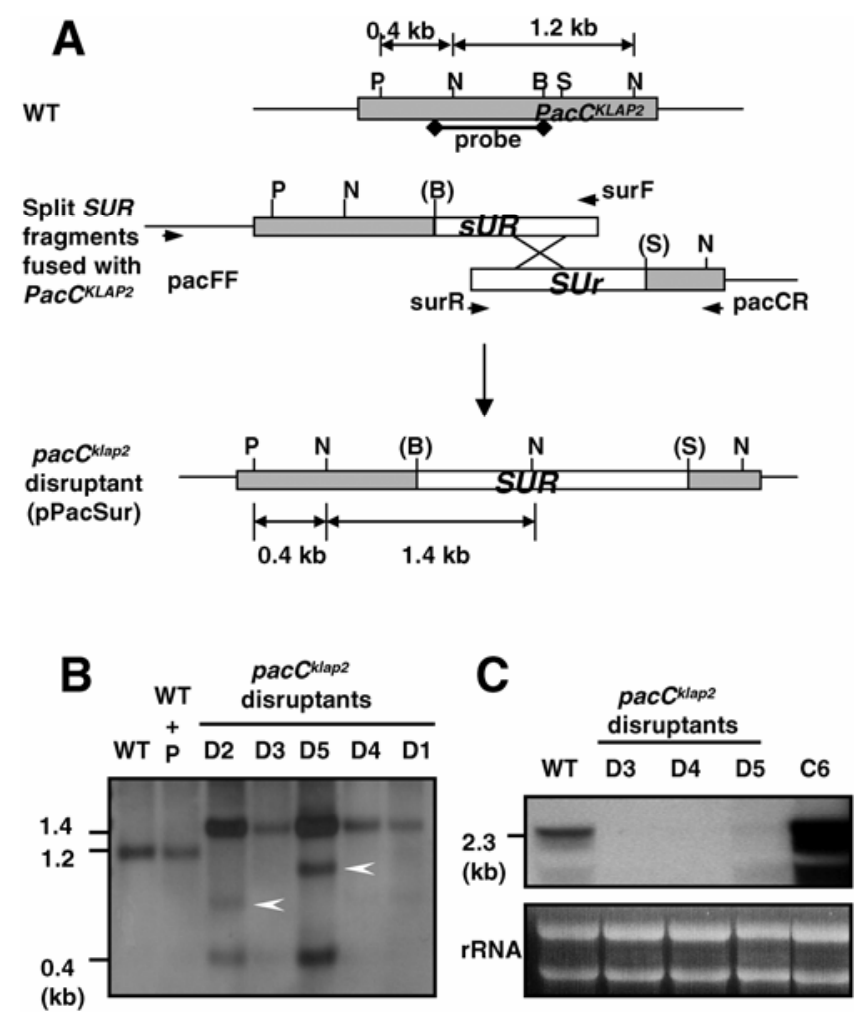

Fig. 3. Functional determination of the Colletotrichum acutatum PacC ${ }^{K L A P 2}$ gene by targeted gene disruption. A, Schematic illustration of restriction map of the PacC $C^{K L A P 2}$ gene (indicated by shading), and the strategy employing split SUR (encoding an acetolactate synthase to confer sulfonylurea resistance) marker to generate DNA fragments for targeted gene disruption in $C$. acutatum. Two truncated PacC $C^{K L A P 2}$ fragments jointed with an overlapping SUR were amplified by primers pacFF/surF and surR/pacCR from a disruption construct (pPacSur), and transformed into the wild type (WT) for gene disruption. Restriction enzyme site abbreviations: B, BglII; N, NheI; P, PstI; and S, SmaI. Sizes of the hybridizing fragments to the probe in Southern blot hybridization and the probe used for Southern and Northern blot analyses also are shown. B, Southern blot hybridization of genomic DNA from WT, WT transformed with plasmid pCB1532 alone $(\mathrm{WT}+\mathrm{P})$, and five putative pac $C^{\text {klap2 }}$ disruptants. Fungal DNA was digested with NheI/PstI, electrophoresed, blotted onto a nylon membrane, and hybridized to a $P a c C^{K L A P 2}$-specific probe. Band patterns validate disruption of the $P a c C^{K L A P 2}$ gene. The $0.4-\mathrm{kb}$ hybridizing band was not detected in some DNA. The probe also hybridized smaller fragments (indicated by arrowheads) in the genome of D2 and D5 transformants, presumably resulting from ectopic integration. C, Northern blot hybridization of total RNA from WT, three pac $C^{\text {klap } 2}$ disruptants, and the PacC $C^{K L A P 2}$-complemented strain (C6). Gel stained with ethidium bromide is shown to indicate the relative amounts of the RNA samples loaded in the gel. Sizes of hybridization bands are indicated in kilobase pairs (kb). 


\section{$P a c C^{K L A P 2}$ is required for fungal growth} at neutral or alkaline $\mathrm{pH}$.

$\mathrm{PacC}^{\mathrm{KLAP2}}$ resembled many fungal PacC/Rim101 orthologs that are responsive to $\mathrm{pH}$ and are involved in a wide range of gene regulation. The T240 strain, but not T42, derived from Agrobacterium-mediated mutagenesis reduced growth drastically on a medium with $\mathrm{pH}$ higher than 6 . Radial growth of wild-type, the pac $C^{k l a p 2}$ disruptants (D3, D4, and D5), and the complemented strains (C26 and C27) on media with various $\mathrm{pH}$ values was compared over time to determine whether $\mathrm{PacC}^{\mathrm{KLAP2}}$ was involved in ambient $\mathrm{pH}$ regulation (Fig. 4). Only one representative replicate of the pac $C^{k l a p 2}$ disruptant and the complemented strain is shown in Figure 4. At $\mathrm{pH} \mathrm{4,}$ growth of the pac $C^{k l a p 2}$-disrupted mutants was reduced by an average of $9 \%$ compared with the wild-type and complemented strains 7 days postinoculation (dpi) (Fig. 4A). Growth inhibition became more obvious when the pac $C^{\text {klap } 2}$ disruptants were grown on PDA buffered to $\mathrm{pH} 6$ (Fig. 4B). At $\mathrm{pH} 8$, growth of the pac $C^{\text {klap } 2}$ disruptants failed to improve, whereas the complemented strains exhibited growth comparable with the wild type (Fig. 4C). Similar growth reduction also occurred when the fungal isolates were grown on complete medium or minimal medium buffered to $\mathrm{pH} 6$ and 8 (data not shown). In

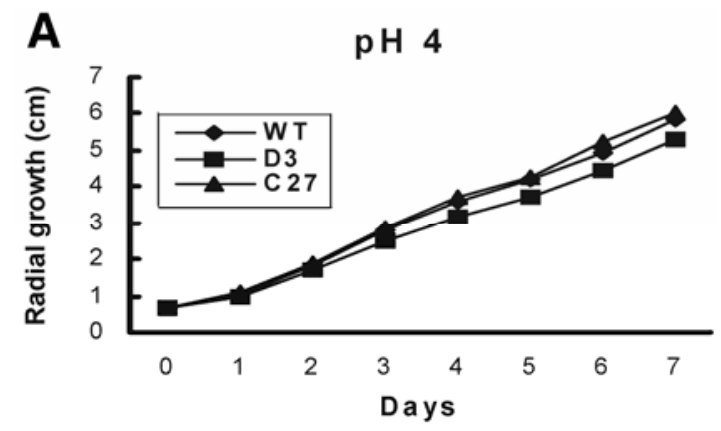

B
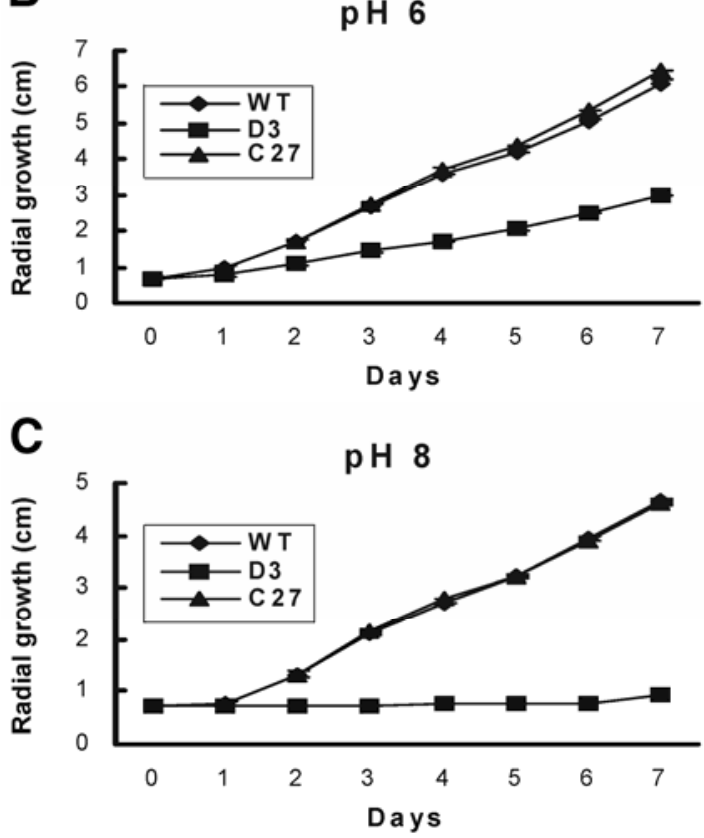

Fig. 4. Radial growth of Colletotrichum acutatum wild type (WT), the pac $C^{\text {klap2 }}$ disruptant (D3), and the Pac $C^{K L A P 2}$-complemented strain (C27) on potato dextrose agar buffered at $\mathrm{pH} 4,6$, or 8 . Fungal growth was determined by measuring the colony diameter over time. Each point is the mean \pm the standard deviation of colony diameter from the independent experiments with at least five replicates. Only one representative replicate of the pac $C^{\text {klap } 2}$ disruptant and the complemented strain is shown. all cases, the $\mathrm{pH}$ of medium increased slightly 7 dpi (data not shown).

\section{Disruption of $\mathrm{PacC}^{K L A P 2}$ affects formation and germination of conidia and appressoria.}

Compared with the wild type, the pac $C^{k l a p 2}$ disruptants produced fewer conidia in culture (Table 1). Conidia were recovered from leaf surfaces 2 dpi and examined by microscopy. The conidia of the $p a c C^{k l a p 2}$ disruptants geminated more rapidly than the wild type. The pac $C^{\text {klap2 }}$ disruptants produced normal appressoria similar to the wild type. However, the conidia of the pac $C^{k l a p 2}$ disruptants formed appressorium frequently after germination, by as much as $40 \%$, compared with the progenitor (Table 1). Transformation of a functional copy of PacC $C^{K L A P 2}$ into a null mutant fully restored formation and germination of conidia and formation of appressoria at a rate similar to the wild type (Table 1).

\section{$\mathrm{PacC}^{\mathrm{KLAP2}}$ is essential for regulation of full virulence.}

Pathogenicity tests using agar plugs on detached Key lime leaves revealed that the T240 mutant induced moderate anthracnose lesions compared with the wild type. To determine whether $P a c C^{K L A P 2}$ mutation was the primary gene responsible for reduction of pathogenic phenotype in T240 mutant, conidia from wild-type, the pac $C^{k l a p 2}$-disrupted mutants and the PacC ${ }^{K L A P 2}$ complemented strains were inoculated onto Key lime leaves, and progression of lesions were evaluated. The wild type incited typical lime anthracnose lesions on Key lime leaves 3 dpi (Fig. 5A). The necrotic lesions caused by the wild type became coalescent to form more conspicuous necrosis $5 \mathrm{dpi}$. In contrast, the majority of spots inoculated with the pac $C^{k l a p 2}$-disrupted mutants failed to develop visible lesions $7 \mathrm{dpi}$. Occasionally, the pac $C^{k l a p 2}$-disrupted mutants incited noticeable necrosis 3 dpi; however, it was limited to less than $4 \%$ of the total leaves inoculated (Fig. 5A). Pathogenicity assays on wounded leaves revealed that the pac $C^{k l a p 2}$-disrupted mutants were capable of inciting necrotic lesions similar to those of the wild type when leaves were wounded prior to inoculation (Fig. 5B). The PacC $C^{K L A P 2}$-complemented strains induced lesion formation comparable with those of the wild type (Fig. 5C).

To assess whether leaf age would affect lesion development, conidial suspensions were inoculated side by side onto Key lime leaves, comprising over 180 leaves of various ages and sizes. Each leaf contained five spots of the isolate and development of necrotic lesions was monitored daily. Over $80 \%$ of the spots inoculated with the wild-type and the complemented strain developed necrotic lesions at $4 \mathrm{dpi}$, and the remaining spots showed lesions at $7 \mathrm{dpi}$ (Fig. 6A). In contrast, less than $8 \%$ (approximately 36 of 450 ) of leaves inoculated with the pac $C^{\text {klap } 2}$ disruptants developed necrotic lesions at $4 \mathrm{dpi}$, which accounted for $40 \%$ of the total inoculated spots. The rest of the

Table 1. Deletion of the $P a c C^{K L A P 2}$ gene affects formation and germination of conidia and appressorium formation in Colletotrichum acutatum ${ }^{\mathrm{a}}$

\begin{tabular}{lccc}
\hline Isolates & $\begin{array}{c}\text { No. of conidia per } \\
\text { ml in culture }\end{array}$ & $\begin{array}{c}\text { Conidia } \\
\text { germination } \\
(\boldsymbol{\%})\end{array}$ & $\begin{array}{c}\text { Appressoria } \\
\text { formation from the } \\
\text { germinated conidia } \\
(\boldsymbol{\%})\end{array}$ \\
\hline WT & $1.4 \pm 0.2 \times 10^{8}$ & $5.5 \pm 3.0$ & $14.2 \pm 12.5$ \\
D3 & $3.9 \pm 0.1 \times 10^{7}$ & $6.9 \pm 1.4$ & $53.2 \pm 6.1$ \\
D4 & $4.3 \pm 0.2 \times 10^{7}$ & $7.0 \pm 1.2$ & $51.7 \pm 5.1$ \\
C27 & $1.47 \pm 0.07 \times 10^{8}$ & $5.9 \pm 0.4$ & $22.3 \pm 4.0$ \\
\hline
\end{tabular}

${ }^{a}$ Conidial suspensions prepared from the wild type (WT), the pac $C^{\text {klap } 2}$ disruptants (D3 and D4), and the complementation strain (C27) of $C$. acutatum were inoculated onto Key lime leaves, recovered, and examined by microscopy at 2 days postinoculation. The data are shown as the mean of at least two different experiments with three replicates. 
leaves inoculated with the $p a c C^{k l a p 2}$ disruptants remained symptomless at 7 dpi (Fig. 6A).

The KLA isolates of $C$. acutatum are pathogenic to flower petals. To determine whether mutation in Pac $C^{K L A P 2}$ would affect pathogenicity on flowers, calamondin trees were stimulated to produce off-season flowers and tested for lesion formation under greenhouse conditions. The results indicated that the necrotic lesions induced by the pac $C^{k l a p 2}$ disruptants were less severe compared with those caused by the wild type 2 dpi (Fig. 6B). The differences in severity became more obvious at $4 \mathrm{dpi}$.

\section{The pac $C^{k l a p 2}$ disruptants are arrested}

\section{in the penetration phase.}

Light microscopy revealed that inoculation of the wild type resulted in a complete destruction of host tissues at 2 to $3 \mathrm{dpi}$, in which epidermal layers and cellular organelles were deformed and fungal infection hyphae and appressoria were present (Fig. 7A). In contrast, inoculation of the pac $C^{\text {klap } 2}$ null mutants did not cause obvious tissue degradation, and the mutants largely remained on the epidermal layers when assessed at 3 dpi (Fig. 7B). Analysis using transmission electron microscopy (TEM) also revealed that the pac $C^{k l a p 2}$ null mutants failed to initiate penetration; the mutant hyphae were completely re-
A
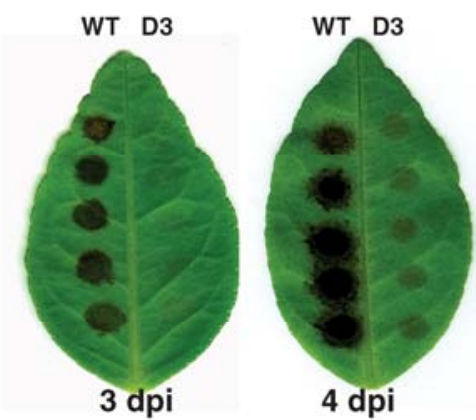

$4 \mathrm{dpi}$

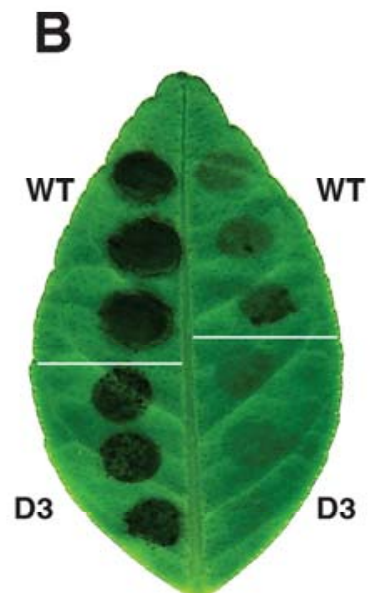

\section{Wounded Unwounded} 2 dpi
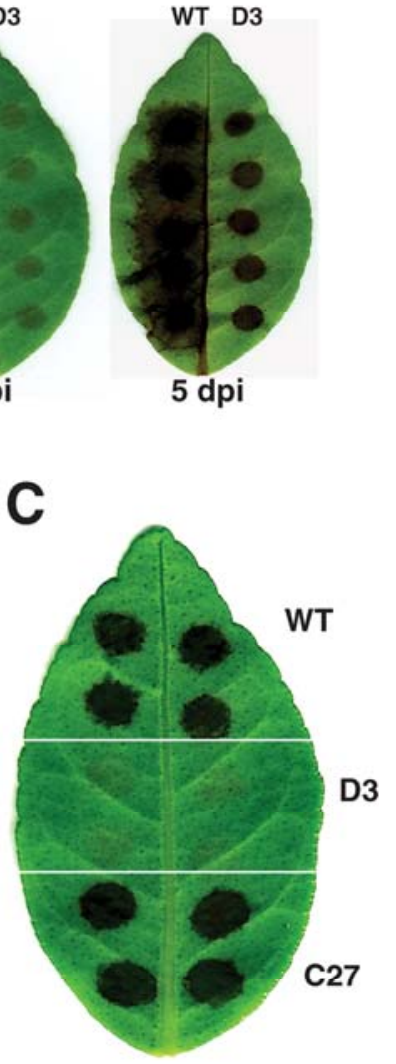

3 dpi
Fig. 5. Pathogenicity assays on detached Key lime leaves with wild type (WT), the pac $C^{\text {klap2 }}$ disruptant (D3), and the Pac $C^{K L A P 2}$-complemented strain (C27) of Colletotrichum acutatum. Only one representative replicate of the pac $C^{k l a p 2}$ disruptant and the complemented strain is shown. A, Conidia were harvested from 5-day-old cultures and inoculated onto Key lime leaves. The leaves were maintained in moist chambers and monitored daily for lesion development. B, Development of necrotic lesions by WT and the $p a c C^{k l a p 2}$ disruptant on Key lime leaves with or without wounding prior to inoculation 2 days postinoculation (dpi). C, Transformation of a functional copy of Pac $C^{K L A P 2}$ into the D3 disruptant restored fungal pathogenicity on Key lime, as evidenced by the C27 complementation strain. stricted to the leaf surfaces and host tissues remained intact (Fig. 7C and D).

\section{$P a c C^{K L A P 2}$ is required for regulation}

of the production of extracellular enzymes.

In addition to pathogenicity deficiency, the pac $C^{\text {klap2 }}$ disruptants also were defective in other physiological functions. The wild-type strain of $C$. acutatum had strong alkaline phosphatase activity, yet the acid phosphatase activity was barely detectable (Fig. 8A and B). Deletion of the PacC $C^{K L A P 2}$ gene resulted in fungal isolates that showed lower alkaline phosphatase but higher acid phosphatase activity (Fig. 8A and B). The $\mathrm{PaCC}^{K L A P 2}$-complemented strain clearly revered the phosphatase activity profiles similar to the wild type. The total proteolytic activity was almost undetectable in the null mutants, whereas wild-type and complemented strains had strong proteolytic activities (Fig. 8C). Deletion of the PacC $C^{K L A P 2}$ gene, however, yielded fungal isolates that had significantly higher levels of the total lipolytic activity, whereas wild-type and complemented strains had lower lipolytic activities (Fig. 8D). Wildtype and complemented strains had much lower levels of pectinase and polygalacturonase activities when grown on a medium containing pectin or polygalacturonic acid as the sole carbon
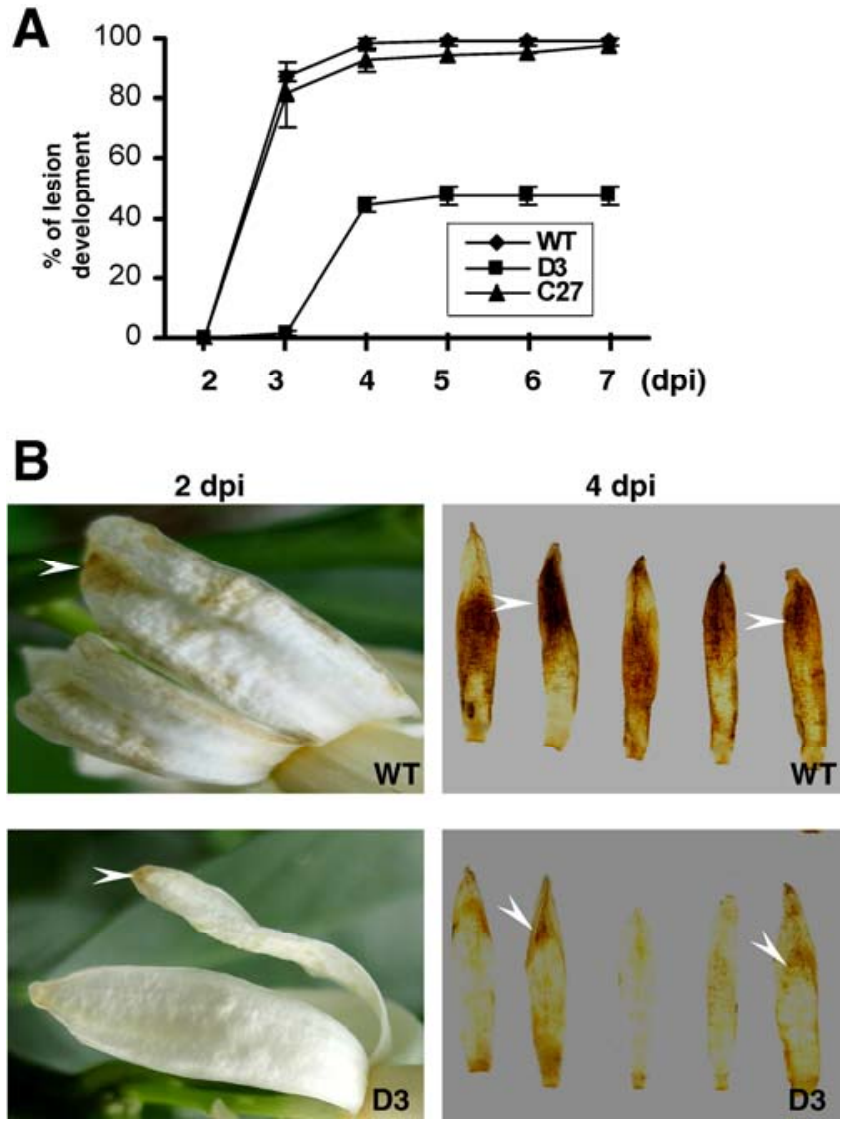

Fig. 6. A, Quantitative analysis of lesion formation by wild type (WT), the $p_{a c} C^{k l a p 2}$ disruptant (D3), and the Pac $C^{K L A P 2}$-complemented strain (C27) of Colletotrichum acutatum on detached Key lime leaves. Conidial suspensions of fungal isolates were inoculated side by side on detached leaves, with five droplets of the isolate on each leaf. Overall, more than 450 spots distributed in $>180$ leaves for each isolate were inoculated. The leaves were kept in moist chambers and monitored daily for lesion formation. Each point represents the total number of spots displaying lesions over the total number of spots inoculated with each fungal isolate. B, Pathogenicity assays with WT and the pac $C^{\text {klap2 } 2}$ disruptant (D3) on the flowers of calamondin trees. Formation of water-soaked lesions is indicated by arrowheads 2 days postinoculation (dpi). Severity of the lesions became more distinct at $4 \mathrm{dpi}$. 

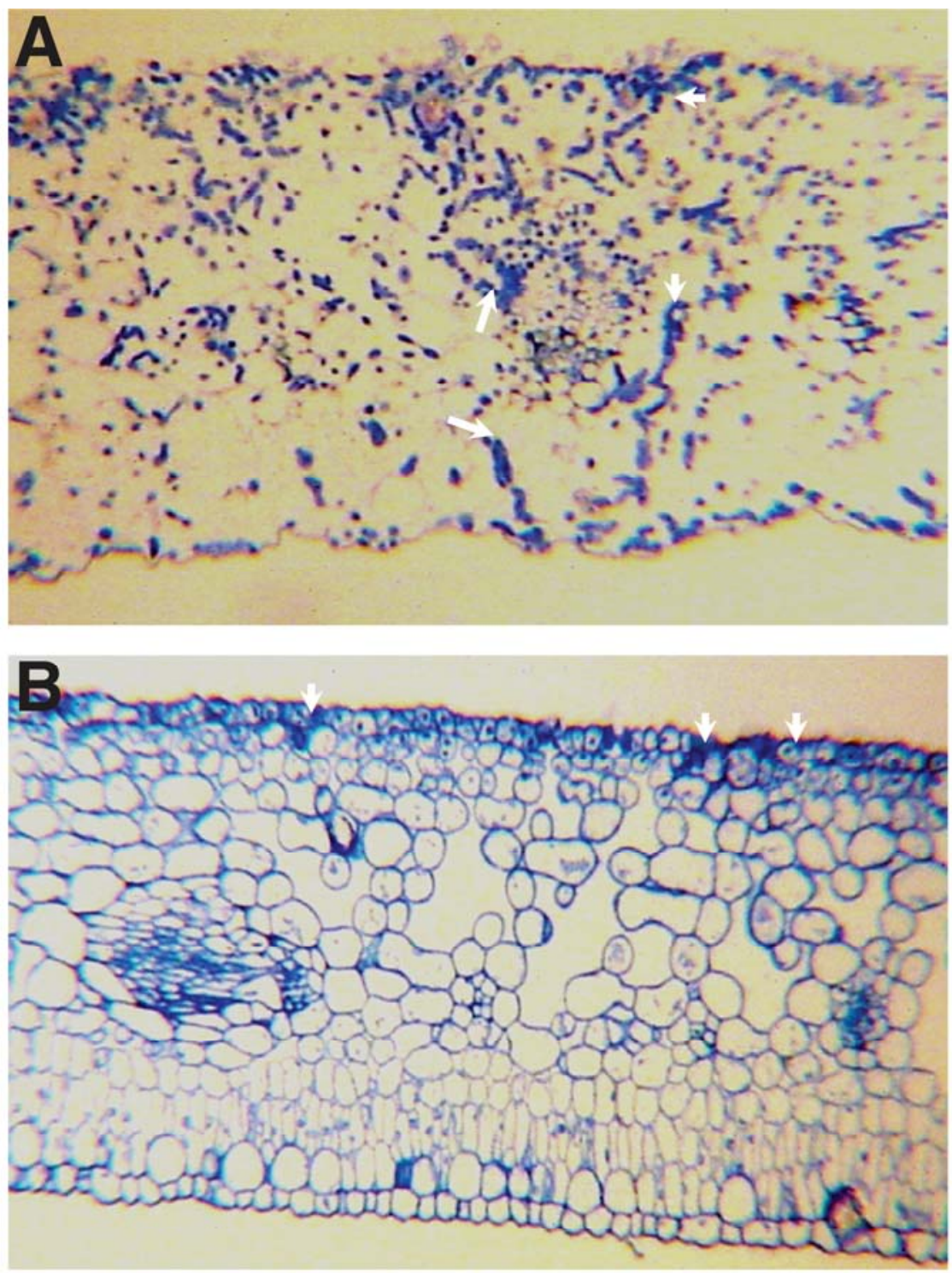

\section{$2 \mu \mathrm{m}$}
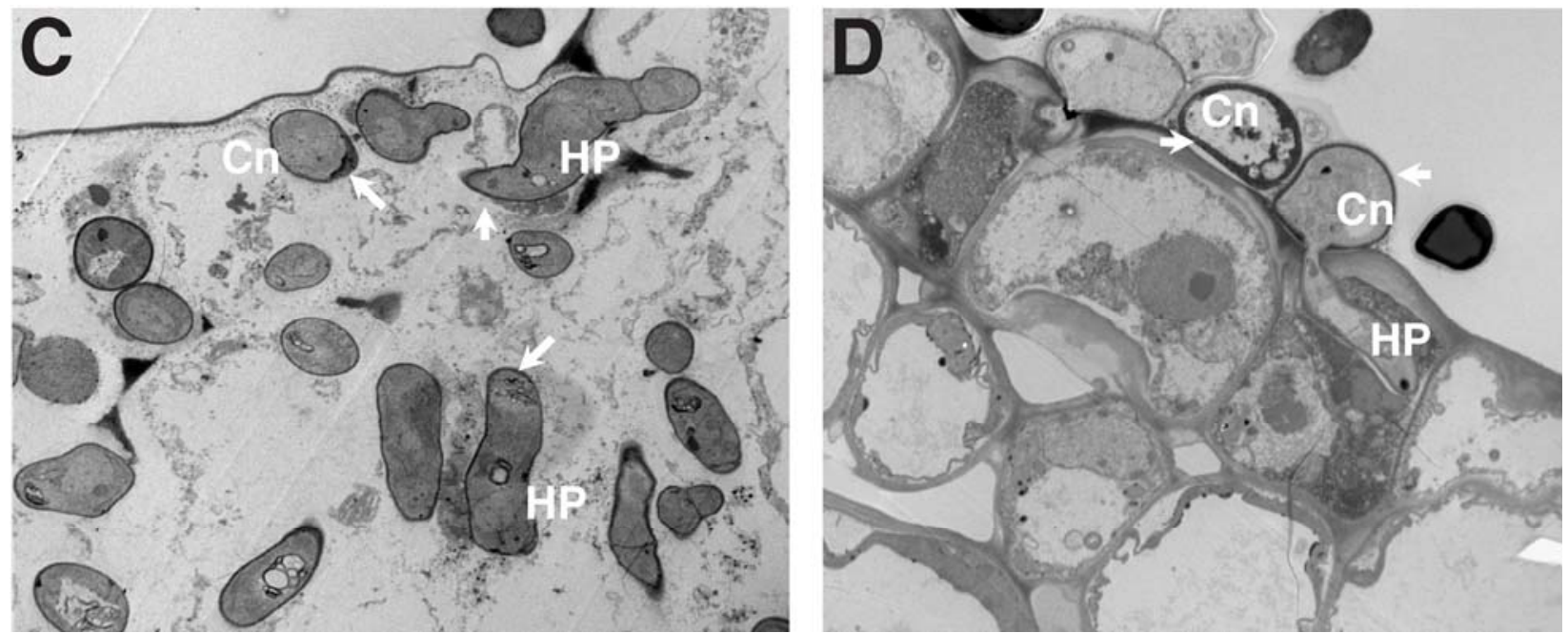

Fig. 7. Light microscopy of Key lime leaves inoculated with A, wild type (WT) Colletotrichum acutatum 3 days postinoculation (dpi), showing deformed epidermal layers and cellular organelles of host plant, and fungal infection hyphae and appressoria. Inoculation of the B, pacC $C^{k l a p 2}$ disruptant onto Key lime leaves (D3) shows no sign of tissue destruction and fungal hyphae within the host. Transmission electron microscopy of Key lime leaves inoculated with C, WT and the D, pac $C^{k l a p 2}$ disruptant (D3) 3 dpi. Inoculation with WT resulted in tissue degradation and fungal hyphal extension. In contrast, the pac $C^{k l a p 2}{ }_{-}$ null mutants apparently failed to penetrate the epidermal layers and was completely restricted to the leaf surfaces, and host tissues remained intact. Fungal hyphae (HP) and conidia ( $\mathrm{Cn}$ ), after staining with methylene blue-Azure A, are indicated by arrowheads. 
source regardless in the acid or alkaline conditions (Fig. 8E and F). The pac $C^{k l a p 2}$ null mutants displayed stronger pectolytic activities, particularly when grown in acid conditions.

Expression of the PacC $C^{K L A P 2}$ gene in axenic culture and in planta.

Northern blot analyses were conducted to determine whether accumulation of the $P a c C^{K L A P 2}$ gene transcript was responsive to $\mathrm{pH}$ in culture. The $P a c C^{K L A P 2}$ gene transcript was accumulated abundantly when the fungus was grown at $\mathrm{pH}$ higher than 5 (Fig. 9A). At acidic $\mathrm{pH}(\leq 4)$, the PacC $C^{K L A P 2}$ gene transcript was barely detectable, but was accumulated to high levels at neutral or alkaline $\mathrm{pH}$. Expression of the $P a c C^{K L A P 2}$ gene was evaluated after inoculation of Key lime leaves (Fig. 9B), showing that the gene transcript was detected sparsely $24 \mathrm{~h}$ after inoculation, but was accumulated in abundance at 2 to $3 \mathrm{dpi}$. To determine fungal biomass in planta, RNA was hybridized to an actin gene probe, revealing that the fungal population reached high levels 2 dpi and remained steady thereafter (Fig. 9B). Thus, accumulation of the $\mathrm{PacC}^{K L A P 2}$ gene transcript was well correlated with the time of lesion formation. The $\mathrm{pH}$ values of citrus leaves in the absence of fungal inoculum were between 5.6 and 6.5 after being extracted with water.

\section{DISCUSSION}

Agrobacterium-mediated transformation recently has been used to transform or disrupt genes in many fungal species
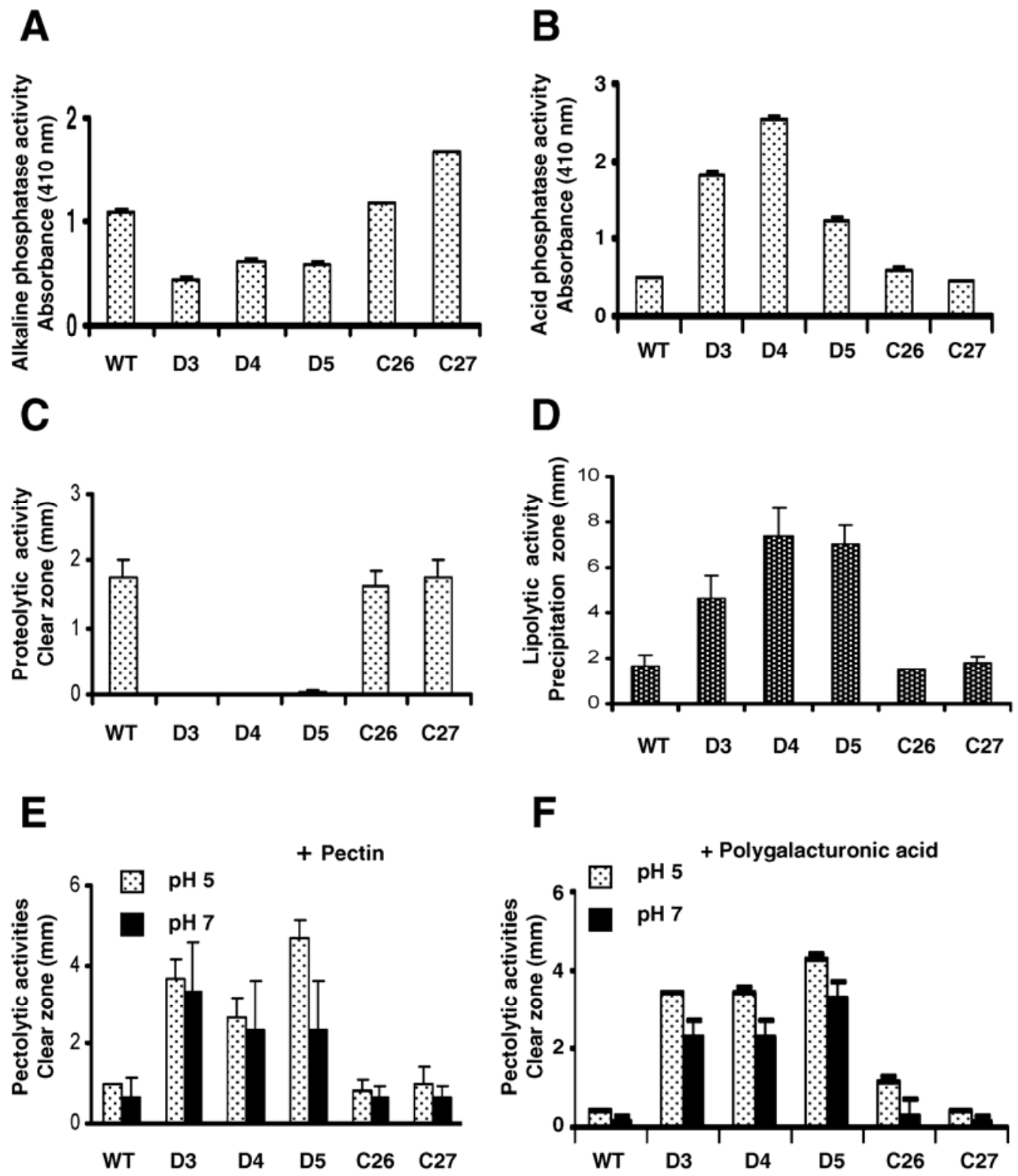

Fig. 8. Production of extracellular enzymes by the wild type (WT), the $p_{a c} C^{k l a p 2}$ null mutants (D3, D4, and D5), and the PacC ${ }^{K L A P 2}$-complemented strains (C26 and C27) of Colletotrichum acutatum. A, Reduction of the alkaline phosphatase activities in the pacC ${ }^{\text {klap } 2}$ null mutants. B, Increase of the acid phosphatase activities in the $p a c C^{k l a p 2}$ null mutants. The phosphatase activities were determined by measuring the amount of the colored complex $p$-nitrophenol from the substrate $p$-nitrophenylphosphate at $410 \mathrm{~nm}$. C, Suppression of the overall proteolytic activities in the pac $C^{\text {klap } 2}$ null mutants. The proteolytic activities were determined by producing a clear zone around the fungal colonies grown on a medium containing $10 \%$ skim milk. D, Stimulation of the overall lipolytic activities in the pac $C^{k l a p 2}$ null mutants. The lipolytic activity was determined by showing a precipitation zone around fungal colonies in the presence of $1 \%$ Tween 20. E, Increase of the pectinase activities in the pac $C^{k l a p 2}$ null mutants at $\mathrm{pH} 5$ or 7 . $\mathbf{F}$, Increase of the polygalacturonase activities in the pac $C^{\text {klap } 2}$ null mutants. The pectolytic activities were determined by measuring the size of clear halos, after flooding with $1 \%$ hexadecyltrimethyl ammonium bromide solution, around fungal colonies grown in a medium containing $\mathbf{E}, 1 \%$ citrus pectin or $\mathbf{F}, 1 \%$ polygalacturonic acid as the sole carbon source. 
(Michielse et al. 2005). In the present study, we utilized Agrobacterium-mediated mutagenesis to explore the unique or common genetic factors that govern pathogenicity of $\mathrm{C}$. $\mathrm{acu}$ tatum in relation to lesion formation on Key lime leaves and orange flowers. We used the KLA isolates because they also are pathogenic to sweet orange flowers, inducing PFD and the formation of calyces similar to the PFD isolates (Chen et al. 2005, 2006; Timmer et al. 1994).

As with other PacC/Rim101 orthologs (Caddick et al. 1986; Denison et al. 1995; Espeso et al. 1993; Negrete-Urtasun et al. 1999; Tilburn et al. 1995, 2005), deletion of PacC $C^{K L A P 2}$ in $C$. acutatum, likely abolishing $\mathrm{pH}$ signal transduction, resulted in fungal mutants that were unable to grow at alkaline $\mathrm{pH}$. Genetic analysis of disruption mutants that occurred specifically at the $P a c C^{K L A P 2}$ locus provides conclusive evidence to support an important role of $P a c C^{K L A P 2}$ during fungal pathogenesis on Key lime leaves and on citrus flowers. In this study, we observed that expression of the $P a c C^{K L A P 2}$ gene was regulated differentially by $\mathrm{pH}$ in culture and occurred in coordination with lesion formation on Key lime leaves, further suggestive of the critical requirement of $P a c C^{K L A P 2}$ for virulence. The importance of $\mathrm{pH}$ regulation in favoring the production and secretion of a pectolytic enzyme during fungal pathogenesis also has been shown in C. gloeosporioides, causing postharvest anthracnose of avocado fruit (Yakoby et al. 2000).

The deduced amino acid sequences of $\mathrm{PacC}^{\mathrm{KLAP} 2}$ have three sets of $\mathrm{C}_{2} \mathrm{H}_{2}$-type zinc finger, with a conserved hydrophobic residue ( $\mathrm{L}$ or $\mathrm{I}$ ) at the fourth residue of the putative $\alpha$-helix (Klug and Rhodes 1987) that might serve as important DNAbinding motifs. The structure of zinc finger-DNA recognition has been investigated in detail and the DNA recognition helices are involved in base-specific binding in A. nidulans (Espeso et al. 2003; Pavletich and Pabo 1991; Tilburn et al. 2005). PacC/ Rim101 orthologs have been shown to bind to the core hexanucleotides 5'-GCCA(G/A)G-3' and mediate $\mathrm{pH}$ regulation (Espeso et al. 2000). PacC/Rim101 functioning via transcriptional activation or suppression regulates numerous physiological functions, including growth, differentiation, and virulence, in several yeasts and fungal pathogens of humans, plants, and insects (Espeso et al. 2000; Peñalva and Arst 2002; Suarez and Peñalva 1996; Tilburn et al. 1995, 2005; Vincent et al. 2003). As for PacC/Rim101, the 5' end nontranslated region of $P a c C^{K L A P 2}$ has multiple core sequences, indicating autoregulation for expression of the $P a c C^{K L A P 2}$ gene in C. acutatum. Northern hybridization analysis also revealed that the $P a c C^{K L A P 2}$ gene was expressed preferentially at $\mathrm{pH}$ values between 5 and 7.

In common with many PacC/Rim101 transcription factors, $\mathrm{PacC}^{\mathrm{KLAP} 2}$ contains other conserved signatures (Fig. 2). Many of these consensus motifs have been considered essential for $\mathrm{PacC} / \mathrm{Rim} 101$ function in response to environmental $\mathrm{pH}$ signaling, subsequently leading to gene regulation (Arst and Peñalva 2003; Tilburn et al. 1995). These conserved residues might be important for the function of $\mathrm{PacC}^{\mathrm{KLAP} 2}$, probably by maintaining subtle configuration and appropriate proteolytic processing of $\mathrm{PacC}^{\mathrm{KLAP} 2}$ as its orthologs in A. nidulans (Arst and Peñalva 2003). Depending on the deleted region, mutations within PacC resulted in the acidity-, neutrality-, or alkalinitymimicking phenotype in $A$. nidulans and caused a wide range of physiological changes (Mingot et al. 1999).

Signaling via extracellular $\mathrm{pH}$ in changing gene expression has been studied in a wide range of microorganisms. $\mathrm{PacC} / \mathrm{Rim} 101$ is involved in $\mathrm{pH}$-mediated regulation of numerous genes and is the central protein of such signaling transduction pathways (Arst and Peñalva 2003; Davis 2003; Peñalva and Arst 2002). Thus, PacC/Rim101 is considered to be one of the global transcription regulators in fungi. In A. nidulans, regulation of gene expression by ambient $\mathrm{pH}$ is modulated by a conversed pathway, involving the polypeptides of at least six Pal genes $(A, B, C, F, H$, and $I)$ that function synergistically to activate the zinc finger transcription regulator PacC/Rim101 (Caddick et al. 1986; Denison et al. 1995; Espeso et al. 1993; Negrete-Urtasun et al. 1999; Tilburn et al. 2005). Mutations in any of the $\mathrm{Pal}$ genes result in fungal mutants that fail to activate $\mathrm{PacC}$, and enable fungal strains to grow at acidic $\mathrm{pH}$ and produce higher levels of acid phosphatase, yet lower levels of alkaline phosphatase. Under alkaline conditions, the acid $\mathrm{C}$ terminus of PacC/Rim101 is processed proteolytically to produce a functional transcription factor that simultaneously activates genes favorably expressed at alkaline $\mathrm{pH}$ and represses genes preferentially functioned at acidic pH (Díez et al. 2002; Espeso et al. 1993, 2000; MacCabe et al. 1998; Mingot et al. 1999; Orejas et al. 1995; Tilburn et al. 2005). Deletion of $\mathrm{PacC} / \mathrm{Rim} 101$ results in strains that not only grow poorly under alkaline $\mathrm{pH}$ but also lead to pleiotropic deficiencies (Peñalva and Arst 2004). As demonstrated in A. nidulans and other fungi, expression of the genes encoding endoxylanses, permeases, cell wall-degrading enzymes such as polygalacturonases, and other secreted enzymes such as proteases and phosphatases are regulated by PacC/Rim101 (Caddick et al. 1986; Hutchings et al. 1999; MacCabe et al. 1998; Manteau et al. 2003; Yakoby et al. 2000). It has been demonstrated or suggested that enzymes involved in the biosynthesis and secretion of toxins and secondary metabolites, including aflatoxin, cephalosporin, fumonisins, oxalic acid, penicillin, and sterig-
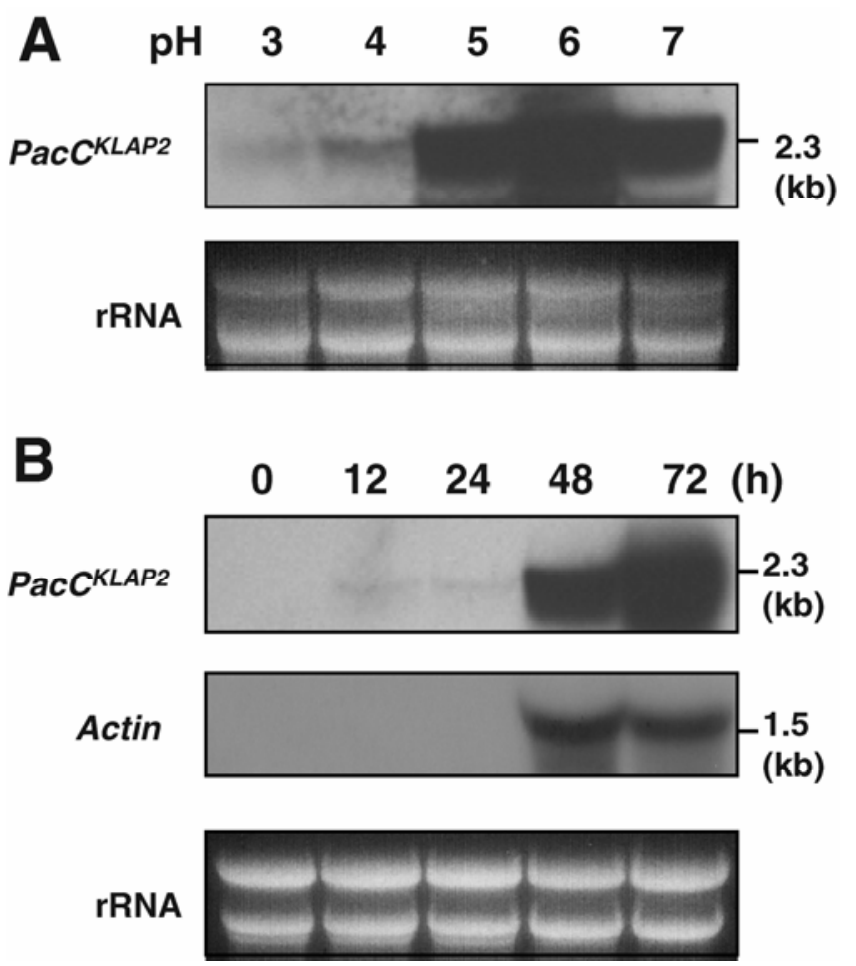

Fig. 9. Northern blot hybridization to assess the accumulation of the PacC $C^{K L A P 2}$ transcript in the wild-type strain of Colletotrichum acutatum. A, Fungal isolate was grown first on nonbuffered potato dextrose broth for 3 days, washed with sterile water, shifted to media buffered with a $0.1 \mathrm{M}$ citric acid and $0.2 \mathrm{M}$ dibasic sodium phosphate solution to $\mathrm{pH} 3,4,5$, 6, or 7 , and incubated for an additional $12 \mathrm{~h}$. Total RNA was purified and subsequently hybridized to a $P a c C^{K L A P 2}$-specific probe. B, Fungal RNA was purified from the inoculated Key lime leaves over time and hybridized to a $P a c C^{K L A P 2}$ or fungal actin gene probe as indicated. Gel stained with ethidium bromide is shown to indicate the relative amounts of the RNA samples loaded in the gel. Sizes of hybridization bands are indicated in kilobase pairs $(\mathrm{kb})$. 
matocystin, are directly or indirectly controlled by $\mathrm{PacC}$ (Flaherty et al. 2003; Keller et al. 1997; Ramón et al. 1999; Rollins 2003; Schmitt et al. 2001; Suarez and Peñalva 1996). In addition to those physiological functions, PacC also is responsible for positive or negative regulation of the genes involved in fungal development and virulence (Are'chiga-Carvajal and Ruiz-Herrera 2005; Bignell et al. 2005; Davis 2003; Li and Mitchell 1997; Ramón et al. 1999; Rollins 2003).

As with other fungi, we also observed that $\mathrm{PacC}^{\mathrm{KLAP} 2}$ positively regulated expression of the genes required for fungal growth, production of conidia, alkaline phosphatase, and proteolytic activities, but negatively regulated acid phosphatase, pectinases, polygalacturonases, and lipolytic activities (Fig. 8). Thus, we predict that the effect of the PacC ${ }^{K L A P 2}$ mutation leading to a reduced virulence on Key lime leaves and citrus flowers could be the consequence of alterations in multiple physiological and pathological functions in C. acutatum.

Surprisingly, deletion of $P a c C^{K L A P 2}$ induced a higher percentage of appressorium formation on Key lime leaves (Table 1). The appressorium is a critical structure for penetration of many fungi into their host plants. The $C$. acutatum KLA pathotype is necrotrophic and obtains most of the nutrients from dead host tissues. It has been suggested but never demonstrated that appressorium is required for a direct penetration into the vegetative tissues by the KLA pathotype (Peres et al. 2005). In contrast, the PFD pathotype does not appear to invade citrus tissues depending on appressoria (Timmer et al. 1994). Instead, appressoria serve as a resting structure during the quiescent stage and are induced to germinate and produce secondary conidia by the chemical signals of the hosts to initiate penetration. The KLA pathotype could penetrate only young leaves of Key lime and exhibited a quiescent infection on the older leaves. This study also revealed that the pac $C^{\text {klap2 }}$ disruption mutants produced a large quantity of appressoria but failed to efficiently penetrate the host tissues. Thus, appressoria produced by the KLA pathotype were not involved in early penetration but likely served as an important structure for fugal survival during adverse conditions.

The pac $^{\text {klap2 }}$ disruption mutants apparently were able to colonize the host tissues once the penetration barriers were removed. Wounding of Key lime leaves prior to inoculation allowed the pac $C^{\text {klap2 }}$ null mutants to colonize and induce necrotic lesions indistinguishable from the wild type. There were no significant differences in the necrotrophic stage between the wild type and the pac $C^{\text {klap } 2}$ null mutants. Light microscopy and TEM directly observing disease progress and fungal structures also supported the conclusion that the pac $C^{\text {klap2 }}$ null mutants were arrested at the penetration stage and, thus, failed to initiate the necrotrophic lifestyle. The inability of the pac $C^{\text {klap2 }}$ null mutants to penetrate Key lime leaves might be due partially to the deficiencies in the cell-wall-degrading enzymes. Assays for enzymatic activities revealed that the pac $C^{\text {klap2 }}$ null mutants had much higher levels of acid phosphatases, pectinases, polygalacturonases, and lipolytic activities but had lower alkaline phosphatase and protease activities compared with the progenitor strain. This suggests that proteolytic enzymes might be required for $C$. acutatum pathogenesis, whereas pectolytic or lipolytic enzymes apparently might not be a crucial virulence determinant.

In a prior study, we showed that the KLAPl gene encoding a novel $\mathrm{C}_{2} \mathrm{H}_{2}$-type transcription regulator played a pivotal role in fungal pathogenesis solely for the vegetative tissues of Key lime (Chen et al. 2005). Mutation in KLAP1 yielded fungal isolates that were completely defective in pathogenicity on Key lime but retained pathogenicity to flower petals. Preliminary studies to determine the epistatic relationships between two genes revealed that expression of the $K L A P 1$ gene transcript was not regulated by $\mathrm{PacC} \mathrm{KLAP}^{\mathrm{K} 2}$ because accumulation of the $K L A P 1$ gene transcript remained unchanged in the pac $^{\text {klap2 }}$ null mutants (data not shown). Similarly, expression of the PacC $C^{K L A P 2}$ gene in two klapl disruptants also was not different from the wild type. Thus, KLAP1 and $P a c C^{K L A P 2}$ may represent two distinct transcriptional regulators that govern a set of unique genes in fungal pathogenesis toward citrus flowers. Apparently, $K L A P 1$ regulated only the genes required for infection of Key lime leaves, but not of flower petals (Chen et al. 2005). In contrast, $P a c C^{K L A P 2}$ appears to be a common regulator of virulence determinants that are required for lesion formation and development both on leaves and flowers. It appears that a common set of genes in C. acutatum, particularly those involved in lesion formation on the vegetative tissues of Key lime, was regulated by both KLAP1 and PacC ${ }^{\mathrm{KLAP} 2}$.

Genetic complementation analysis by reintroduction of a functional copy of the $P a c C^{K L A P 2}$ gene into a null mutant fully alleviated the deformed phenotypes associated with the $P a c C^{K L A P 2}$ disruption. The results further confirmed the important role of $P a c C^{K L A P 2}$ in alkaline sensitivity, enzymatic production, and fungal pathogenesis. Involvement of the PacC orthologs in increased fungal virulence has been implied or proven in various pathogens (Are'chiga-Carvajal and RuizHerrera 2005; Bingnell et al. 2005; Davis 2003; Li and Mitchell 1997; Poussereau et al. 2001; Prusky et al. 2001; Ramón et al. 1999; Rollins 2003). However, a PacC ortholog in $F$. oxysporum acts as a negative regulator of virulence on tomato (Caracuel et al. 2003). In this study, the pac $^{k}{ }^{k a p 2}$ null mutants failed to incite anthracnose lesions on most of the leaves inoculated. Thus, the C. acutatum PacC ${ }^{\mathrm{KLAP} 2}$ apparently is a positive regulator, commanding expression of the genes required for fungal pathogenesis. In some tests, a few leaves developed necrotic lesions after inoculation with the pac $C^{k l a p 2}$ null mutants. However, the rate for lesion development was much slower, and the magnitude of lesions was limited to a small portion of leaves compared with those of the wild type. This "residual" infection by the pac $C^{\text {klap2 }}$ disruptants could be attributed to physiological variations between Key lime leaves. Repeated tests using a large quantity of leaves confirmed this speculation because the pac $C^{\text {klap } 2}$ null mutants induced lesions on a limited proportion of the leaves inoculated.

In summary, the PacC ${ }^{\mathrm{KLAP} 2}$ transcriptional regulator might play a profound role in the regulation of genes required for $C$. acutatum pathogenesis because the original mutant T240 was only one of two mutants identified after screening a large number of Agrobacterium-derived transformants for reduced virulence on Key lime leaves. This finding might have practical implications in developing a novel approach, specifically targeting the $P a c C^{K L A P 2}$ signaling pathway to control C. acutatuminduced diseases on citrus in the future.

\section{MATERIALS AND METHODS}

\section{Fungal strains and cultural conditions.}

The wild-type KLA207 strain of $C$. acutatum J. H. Simmonds used in this study as a recipient host for transformation and mutagenesis experiments was previously described (Chen et al. 2005; Chung et al. 2002). Fungal isolates were maintained on PDA (Difco Laboratories, Becton, Dickinson and Company, Sparks, MD, U.S.A.). The $\mathrm{pH}$ of medium was adjusted appropriately with $0.1 \mathrm{M}$ citric acid and $0.2 \mathrm{M}$ dibasic sodium phosphate buffer. Phenotypic analyses were conducted by stabbing colonies with sterile toothpicks and transferring the fungal mycelium onto test media. Complete and minimal media were prepared as described by Jenns and associates (1989). Unless otherwise specified, all chemicals were purchased from Sigma-Aldrich (St. Louis) and dissolved in water or appropri- 
ate solvents to make a stock solution. Radial growth of fungal isolates was measured 3 to $5 \mathrm{dpi}$. For DNA and RNA purification, fungal strains were grown on solid media with a layer of cellophane on the surface. To determine the effect of $\mathrm{pH}$ on gene expression, the $C$. acutatum wild type first was grown in regular potato dextrose broth ( $\mathrm{pH}$ 5.6) (Difco Laboratories) for 3 days, shifted to media with various $\mathrm{pH}$ values, and incubated for an additional $12 \mathrm{~h}$ for RNA isolation.

\section{Agrobacterium-mediated transformation and mutagenesis.}

The Agrobacterium tumefaciens strain harboring the binary plasmid pBHt1, originally developed by Mullins and associates (2001), was kindly provide by J. A. Rollins (University of Florida) and was used for transformation and mutagenesis in $C$. $a c u$ tatum. Plasmid pBHt1 carries a hygromycin phosphotransferase B gene $(H Y G)$ under the Aspergillus nidulans trpC promoter and a chloramphenicol resistance gene cassette. Preparation of Agrobacterium tumefaciens cells and fungal transformation and mutagenesis were conducted according to the protocols described by Mullins and associates (2001), with modifications. Briefly, $C$. acutatum conidia $\left(10^{6} / \mathrm{ml}\right)$ were mixed with an equal volume of Agrobacterium tumefaciens cells; plated onto a medium containing $5 \mathrm{mM}$ glucose, $0.5 \%$ glycerol, and $200 \mu \mathrm{M}$ acetosyringone, with a layer of cellophane; and incubated at $28^{\circ} \mathrm{C}$ for 3 days. The cellophane sheet was transferred onto the $2 \%$ malt extract agar medium amended with hygromycin $(250$ $\mu \mathrm{g} / \mathrm{ml})$, cefotaxim $(100 \mu \mathrm{g} / \mathrm{ml})$, and moxalactum $(100 \mu \mathrm{g} / \mathrm{ml})$ and monitored daily for appearance of fungal colonies. The putative transformants were selected and streaked at least three times for single-conidial colonies on a medium containing hygromycin at $500 \mu \mathrm{g} / \mathrm{ml}$ and tested for fungal pathogenicity on detached Key lime leaves. Transformants were screened for putative mutants defective in pathogenesis using agar plugs (approximately $0.5 \mathrm{~cm}$ in diameter) with fungal conidia and mycelia. Mutants were further confirmed by inoculation using conidial suspensions as described below.

\section{Rescue and sequence analysis of the flanking fragments of T-DNA.}

A TAIL-PCR protocol (Mazars et al. 1991) was used with modifications to recover the flanking genomic sequence of $\mathrm{T}$ DNA insertion sites from the putative mutant (T240). Primers complemented with the border ends of the T-DNA sequence and an arbitrary degenerate primer (5'-WAGTGNAGWANCA NAGA- $3^{\prime}$ ) were synthesized as described by Mullins and associates (2001). A 0.9-kb PCR fragment was amplified directly from the genomic DNA of the mutant T240 with a Titanium Taq DNA polymerase (Clontech Laboratories, Mountain View, CA, U.S.A.) and cloned into pGEM-T easy vector (Promega Corp., Madison, WI, U.S.A.) to become pKLA240 for sequence analysis. PCR was performed using the conditions of Mullins and associates (2001) in a PTC-100 model of thermal cycler (MJ Research, Watertown, MA, U.S.A.). DNA sequencing from both directions was conducted at Eton Bioscience, Inc. (San Diego, CA, U.S.A.). Oligonucleotide primers used for PCR amplification and sequence analysis were synthesized by Integrated DNA Technologies (Coralville, IA, U.S.A.) and Allele Biotechnology and Pharmaceuticals, Inc., (San Diego, CA, U.S.A.), respectively. Database searches were conducted at the National Center of Biotechnology Information using the BLAST network service. ORF and exon or intron positions were predicted using the gene-finding software and validated by comparisons of genomic and cDNA sequences. A search for function domains was conducted in the PROSITE database using the ExPASy Molecular Biology Server and Motif/ProDom and Block programs. Analysis of the promoter region was conducted using regulatory sequence analysis tools.

\section{Cloning of the PacC $\mathrm{CLAP2}^{\mathrm{KL}}$ gene.}

Sequences beyond the rescued fragment in pKLA204 were obtained by chromosome walking. A chromosome library of C. acutatum was prepared from genomic DNA digested with DraI, EcoRI, PvuI, or StuI and ligated to the adaptors with a Universal GenomeWalker kit (Clontech Laboratories). To walk upward and downward into unknown genomic regions, primers were synthesized to complement the known regions and used for two rounds of PCR amplification with adaptor primers supplied with the kit. Two DNA fragments of 2.2 and $1.0 \mathrm{~kb}$ in length were obtained by walking upward and downward, respectively. The amplified DNA fragments were purified with DNA purification kit (Mo Bio Laboratories, Inc., Carlsbad, CA, U.S.A.) and cloned into pGEM-T easy vector for sequence analysis. A 3.5-kb DNA fragment containing the full-length $P a c C^{K L A P 2}$ gene subsequently was amplified from the genomic DNA of $C$. acutatum with primers pacCF (5'-aacgtaaatggacgcg ggtgct- $\left.3^{\prime}\right)$ and pacCR (5'-cctctcttcgacacagacaccagg- $\left.3^{\prime}\right)$, and was cloned into pGEME-T easy vector to generate pPacC. The $P a c C^{K L A P 2}$ ORF was predicted first by a gene prediction analysis with a computer software, and further validated by comparing genomic and cDNA sequences.

\section{Functional analysis of the $\mathrm{PacC}^{K L A P 2}$ gene.}

A disruption plasmid (pPacSur) was constructed to delete the $P a c C^{K L A P 2}$ gene by double crossing-over recombination as follows. A 2.8-kb SUR gene cassette encoding an acetolactate synthase and conferring sulfonylurea resistance was amplified from plasmid pCB1551 or pCB1532 (obtained from the Fungal Genetics Stock Center) with primers sur-1 (5'-gtgcccacatctcccggg tggattcaccg-3') incorporated with an SmaI endonuclease recognition site and sur-2 (5'-acgtgagatcttgcaattccegtgcaataatc- $\left.3^{\prime}\right)$ incorporated with a $B g l I I$ recognition site. After being digested, the $S U R$ gene cassette was inserted into $\mathrm{pPacC}$ to result in $\mathrm{pPac}$ Sur. A split marker recombination strategy was used to enhance gene disruption as previously described (Chen et al. 2005) with some modifications. Two truncated SUR markers fused with either the $5^{\prime}$ or $3^{\prime}$ end of Pac $C^{K L A P 2}$ were amplified, mixed, and directly transformed into protoplasts prepared from the wildtype KLA207 strain for gene disruption. Primers pacFF (5'-ctcg gcagccctcgecacctc- $\left.3^{\prime}\right)$ and surF (5'-actcccatggccgacgctct- $\left.3^{\prime}\right)$ were used to amplify the $5^{\prime} P a c C^{K L A P 2}-3^{\prime} S U R$ fragment $(3.3 \mathrm{~kb})$ and primers pacCR and surR ( $5^{\prime}$-cgaagcaacgtcgccctcaa- $\left.3^{\prime}\right)$ were used to amplify the $5^{\prime} S U R-3^{\prime} P a C C^{K L A P 2}$ fragment $(2.6 \mathrm{~kb})$. Preparation of fungal protoplasts and transformation using $\mathrm{CaCl}_{2}$ and polyethylene glycol were as previously described (Chung et al. 2002). Fungal transformants were selected first on a medium supplemented with sulfonylurea (chlorimuron ethyl; Chem Service, West Chester, PA, U.S.A.) at $10 \mu \mathrm{g} / \mathrm{ml}$ and streaked three times to obtain single-conidial colonies. Targeted gene disruption within $P a c C^{K L A P 2}$ was further confirmed by Southern and Northern blot analyses. For genetic complementation, a PCR fragment containing the entire Pac $C^{K L A P 2} \mathrm{ORF}$ and its endogenous promoter was amplified with pacCF and pacCR primers by an Expand High Fidelity PCR system (Roche Applied Science, Indianapolis, IN, U.S.A.). The amplified products were co-transformed with the plasmid pUCATPH carrying a hygromycin phosphotransferase $\mathrm{B}$ resistance gene cassette under the Aspergillus nidulans trpC promoter into protoplasts of a pac $C^{\text {klap2 }}$-disrupted mutant (D3). Transformants were selected initially on a medium containing hygromycin (Roche Applied Science) at $1 \mathrm{mg} / \mathrm{ml}$, and further confirmed by Northern blot hybridization and pathogenicity assays.

\section{Molecular techniques.}

Plasmids were multiplied in Escherichia coli DH5 $\alpha$ cells, and purified with Wizard DNA purification kit (Promega 
Corp.). Fungal DNA was isolated with DNeasy Plant Mini kit (Qiagen, Valencia, CA, U.S.A.). RNA was extracted with TRIZOL RNA isolation kit (Invitrogen, Carlsbad, CA, U.S.A.). Double-stranded cDNA was synthesized from total RNA with the BD SMART cDNA synthesis kit (Clontech Laboratories). Two overlapping cDNA fragments were amplified with $P_{a c} C^{K L A P 2}$-specific primers and cloned for sequence analysis. Southern and Northern blot analyses, endonuclease digestion of DNA, and electrophoresis were conducted with the standard procedures. The hybridization probe incorporating with digoxigenin (Roche Applied Science) was labeled by PCR with primers pacC-1 (5'-gcaacctgaagtttgtctcaccgg- $\left.3^{\prime}\right)$ and pacC-3 (5'-tgcggtcagcggcgatgcca-3') as previously described (Chung et al. 2003b). The actin gene probe was amplified and labeled with primers actin-F (5'-tggagaagatttggcaccac-3') and actin-R (5'-ataccaccgetttccagacc- $\left.3^{\prime}\right)$ from genomic DNA of A. nidulans and hybridized to $C$. acutatum RNA at $50^{\circ} \mathrm{C}$. Procedures and conditions used for hybridization, posthybridization washing, and immunological detection of the probe with a CSPD chemiluminescence substrate for alkaline phosphatase were performed following the manufacturer's suggestions (Roche Applied Science).

\section{Enzymatic assays.}

The alkaline and acid phosphatase activities were evaluated using 4-p-nitrophenylphosphate as a substrate by the methods of Dorn and Rivera (1966). Fungal mycelia cultured on the nonbuffered PDA were ground into small pieces with disposable pestles and inoculated into $2 \mathrm{ml}$ of liquid minimal medium omitting phosphates. After incubation at $30^{\circ} \mathrm{C}$ for $3 \mathrm{~h}$, cultural filtrates were mixed $(1: 4, \mathrm{vol} / \mathrm{vol})$ with 4 - $p$-nitrophenylphosphate dissolved in 0.6 M Tris buffer $(\mathrm{pH} 9.5$, for

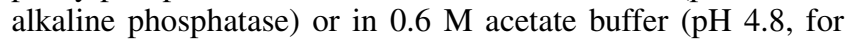
acid phosphatase). The phosphatase activities released by colorimetric $p$-nitrophenol were measured using a spectrophotometer at $410 \mathrm{~nm}$. Assays for proteolytic activities using a $10 \%$ skim milk agar medium (Difco Laboratories) dissolved in $0.05 \mathrm{M}$ phosphate buffer ( $\mathrm{pH}$ 6.8) were carried out as described by Ogrydziak and Mortimer (1977). The enzymatic activities of proteolysis were observed by the formation of a clear zone around the fungal colonies. Assays for pectolytic activities using $1 \%$ pectin or $1 \%$ polygalacturonic acid were conducted in complete medium omitting glucose. The $\mathrm{pH}$ of media was adjusted to 5 or 7 with $0.6 \mathrm{M}$ Tris buffer. Agar plugs with fungal mycelia were inoculated and incubated for 3 days. The plates were overlaid with $1 \%$ hexadecyltrimethyl ammonium bromide. The pectolytic activities were determined by measuring the size of clear halos (Hubbell et al. 1978). Assays for lipolytic activities using $1 \%$ Tween 20 as a substrate were carried out by the methods of Gopinath and associates (2005). The lipolytic activity was determined by the formation of visible precipitation around fungal colonies. All treatments were performed three times with at least three replicates of each treatment.

\section{Pathogenicity assays.}

Infection assays were performed on immature, detached Key lime (Citrus aurantifolia (Christm. et Panz) Swingle) leaves (3 to 5 days after emergence and approximately 3 to $4 \mathrm{~cm}$ in length). Agar plug assays on detached leaves were used to screen for fungal isolates that reduced in pathogenicity after Agrobacterium-mediated transformation. A 6-mm-diameter agar plug was cut from mycelial mats cultured on PDA and placed onto Key lime leaves with the fungal mycelium directly in contacted with the leaf surface. Inoculation assays using conidial suspensions were conducted as previously described (Chung et al. 2002), with modifications. Briefly, fungal conidia were harvested by flooding 5-day-old cultures with sterile water, centrifuging, and adjusting the concentration to $5 \times 10^{6}$ conidia/ml. Inoculated leaves were maintained in a moist chamber and incubated under constant fluorescent lights. Pathogenicity tests on flower petals were conducted on calamondin (Citrus mandurensis Lour) trees grown in 5-gallon pots in a greenhouse, and trees were triggered to produce off-season flowers by drought stress as previously described (Lahey et al. 2004; $\mathrm{Li}$ et al. 2003). Flowers were inoculated with a SpraTool sprayer (Crown, Woodstock, IL, U.S.A.). The inoculated flower clusters were covered with plastic bags for at least $10 \mathrm{~h}$ to allow fungal penetration. The affected petals showed watersoaked, brown lesions 2 to 3 dpi.

\section{Microscopy.}

Germination of conidium and formation of appressorium were assessed microscopically. Fungal isolates were inoculated onto Key lime leaves as described above and recovered from leaves 2 dpi, placed on glass slides, and examined. For TEM, samples were fixed with $3 \%$ glutaraldehyde in $0.1 \mathrm{M}$ phosphate buffer ( $\mathrm{pH} 7.2$ ) and $2 \%$ osmium tetraoxide, and embedded in Spurr's resins after being dehydrated with an acetone series. Samples were sectioned, examined using a Model 268 FEI Morgagni TEM (FEI Company, Hillsboro, OR, U.S.A.) after being stained with uranyl acetate and lead citrate, and photographed with an AMT CCD camera (Advanced Microscopy Techniques Corp., Danvers, MA, U.S.A.). For light microscopy, plant tissues were stained with methylene blue-Azure A at $65^{\circ} \mathrm{C}$ and examined using a Leitz Laborlux phase contrast microscope (Leica Microsystems Inc., Exton, PA, U.S.A.). The images were photographed at 1,024-by-1,024-pixel resolution and exported as TIF files.

\section{ACKNOWLEDGMENTS}

We wish to thank H. Chen for technical assistance, D. Achor for assistance with microscopy, and L. W. Timmer and two anonymous reviewers for helpful comments. This research was supported by the Florida Agricultural Experiment Station and grants from the Florida Citrus Production Research Advisory Council (FCPRAC) \#012-04P and \#033-03P (to K.R.C.).

\section{LITERATURE CITED}

Agostini, J. P., Timmer, L. W., and Mitchell, D. J. 1992. Morphological and pathological characteristics of strains of Colletotrichum gloeosporioides from citrus. Phytopathology 82:1377-1382.

Are'chiga-Carvajal, E. T., and Ruiz-Herrera, J. 2005. The RIM101/pacC homologue from the Basidiomycete Ustilago maydis is functional in multiple pH-sensitive phenomena. Eukaryotic Cell 4:999-1008.

Arst, H. N., Jr., and Peñalva, M. A. 2003. pH regulation in Aspergillus and parallels with higher eukaryotic regulatory systems. Trends Genet. 19:224-231.

Bignell, E., Negrete-Urtasun, S., Calcagno, A. M., Haynes, K., Arst, H. N., Jr., and Rogers, T. 2005. The Aspergillus pH-responsive transcription factor PacC regulates virulence. Mol. Microbiol. 55:1072-1084.

Caddick, M. X., Brownlee, A. G., and Arst, H. N., Jr. 1986. Regulation of gene expression by $\mathrm{pH}$ of the growth medium in Aspergillus nidulans. Mol. Gen. Genet. 203:346-353.

Caracuel, Z., Roncero, M. I. G., Espeso, E. A., González-Verdejo, C. I., García-Maceira, F. I., and Di Pietro, A. 2003. The pH signalling transcription factor PacC controls virulence in the plant pathogen Fusarium oxysporum. Mol. Microbiol. 48:765-779.

Chen, H.-Q., Dekkers, K. L., Rollins, J. A., Ko, N. J., Timmer, L. W., and Chung, K.-R. 2005. A gene with domains related to transcription regulation is required for pathogenicity in Colletotrichum acutatum causing Key lime anthracnose. Mol. Plant Pathol. 6:513-525.

Chen, H.-Q., Dekkers, K. L., Burns, J. K., Timmer, L. W., and Chung, K.R. 2006. Evaluation of growth regulator inhibitors for controlling postbloom fruit drop (PFD) of citrus caused by Colletotrichum acutatum. HortScience 41:1317-1321.

Chung, K.-R., Shilts, T., Li, W., and Timmer, L. W. 2002. Engineering a genetic transformation system for Colletotrichum acutatum, the causal 
fungus of lime anthracnose and postbloom fruit drop of citrus. FEMS (Fed. Eur. Microbiol. Soc.) Microbiol. Lett. 213:33-39.

Chung, K.-R., Shilts, T., Ertürk, Ü., Timmer, L. W., and Ueng, P. P. 2003a. Indole derivatives produced by the fungus Colletotrichum acutatum causing lime anthracnose and postbloom fruit drop of citrus. FEMS (Fed. Eur. Microbiol. Soc.) Microbiol. Lett. 226:23-30.

Chung, K.-R., Daub, M. E., Kuchler, K., and Schüller, C. 2003b. The $C R G 1$ gene required for resistance to the singlet oxygen-generating cercosporin toxin in Cercospora nicotianae encodes a putative fungal transcription factor. Biochem. Biophys. Res. Commun. 302:302-310.

Davis, D. 2003. Adaptation to environmental pH in Candida albicans and its relation to pathogenesis. Curr. Genet. 44:1-7.

Denison, S. H., Orejas, M., and Arst, N. H., Jr. 1995. Signaling of ambient $\mathrm{pH}$ in Aspergillus involves a cysteine protease. J. Biol. Chem. 270:28519-28522.

Díez, E., Álvaro, J., Espeso, E. A., Rainbow, L., Suárez, T., Tilburn, J., Arst, H. N., Jr., and Peñalva, M. Á. 2002. Activation of the Aspergillus PacC zinc-finger transcription factor requires two proteolytic steps. EMBO (Eur. Mol. Biol. Organ.) J. 21:1350-1359.

Dorn, G., and Rivera, W. 1966. Kinetics of fungal growth and phosphatase formation in Aspergillus nidulans. J. Bacteriol. 92:1618-1622.

Espeso E. A., Tilburn, J., Arst, H. N., Jr., and Peñalva, M. Á. 1993. pH regulation is a major determinant in expression of a fungal penicillin biosynthetic gene. EMBO (Eur. Mol. Biol. Organ.) J. 12:3947-3956.

Espeso, E. A., Tilburn, J., SaÂnchez-Pulido, L., Brown, C. V., Valencia, A., Arst, H. N., Jr., and Peñalva, M. Á. 1997. Specific DNA recognition by the Aspergillus nidulans three zinc finger transcription factor PacC. J. Mol. Biol. 274:466-480.

Espeso, E. A., Roncal, T., Díez, E., Rainbow, L., Bignell, E., Alvaro, J., Suarez, T., Denison, S. H., Tilburn, J., Arst, H. N., Jr., and Peñalva, M. Á. 2000. On how a transcription factor can avoid its proteolytic activation in the absence of signal transduction. EMBO (Eur. Mol. Biol. Organ.) J. 19:719-728.

Flaherty, J. E., Pirttilä, A. M., Bluhm, B. H., and Woloshuk, C. P. 2003 PACl, a pH-regulatory gene from Fusarium verticillioides. Appl. Environ. Microbiol. 69:5222-5227.

Gopinath, S. C. B., Anbu, P., and Hilda, A. 2005. Extracellular enzymatic activity profiles in fungi isolated from oil-rich environments. Mycoscience 46:119-126

Hubbell, D. H., Morales, V. M., and Umali-Gracia, M. 1978. Pectolytic enzymes in Rhizobium. Appl. Environ. Microbiol. 35:210-213.

Hutchings, H., Stahmann, K., Roels, S., Espeso, E. A., Timberlake, W. E., Arst, H. N., Jr., and Tilburn, J. 1999. The multiply-regulated gabA gene encoding the GABA permease of Aspergillus nidulans: A score of exons. Mol. Microbiol. 32:557-568.

Jenns, A.E., Daub, M. E., and Upchurch, R. G. 1989. Regulation of cercosporin accumulation in culture by medium and temperature manipulation. Phytopathology 79:213-219.

Keller, N. P., Nesbit, C., Sarr, B., Phillips, T. D., and Burrow, G. B. 1997. $\mathrm{pH}$ regulation of sterigmatocystin and aflatoxin biosynthesis in Aspergillus spp. Phytopathology 87:643-648.

Klug, A., and Rhodes, D. 1987. 'Zinc fingers': A novel protein motif for nucleic acid recognition. Trends Biochem. Sci. 12:464-469.

Kuspa, A. and Loomis, W. F. 1992. Tagging developmental genes in Dictyostelium by restriction enzyme-mediated integration of plasmid DNA. Proc. Natl. Acad. Sci. U.S.A. 89:8803-8807.

Lahey, K. A., Yuan, R., Burns, J. K., Ueng, P. P., Timmer, L. W., and Chung, K.-R. 2004. Induction of phytohormones and differential gene expression in citrus flowers infected by the fungus Colletotrichum acutatum. Mol. Plant-Microbe Interact. 17:1394-1401.

Li, W., Yuan, R., Burns, J. K., Timmer, L. W., and Chung, K.-R. 2003. Genes for hormone biosynthesis and regulation are highly expressed in citrus flowers infected with the fungus Colletotrichum acutatum, causal agent of postbloom fruit drop. J. Am. Soc. Hortic. Sci. 128:578-583.

Li, W. S., and Mitchell, A. P. 1997. Proteolytic activation of Rim1p, a positive regulator of yeast sporulation and invasive growth. Genetics 145:63-73.

MacCabe, A. P., Orejas, M., Perez-Gonzalez, J. A., and Ramon, D. 1998. Opposite patterns of expression of two Aspergillus nidulans xylanase genes with respect to ambient pH. J. Bacteriol. 180:1331-1333.

Manteau, S., Abouna, S., Lambert, B., and Legendre, L. 2003. Differential regulation by ambient $\mathrm{pH}$ of putative virulence factors secretion by the phytopathogenic fungus Botrytis cinerea. FEMS (Fed. Eur. Microbiol. Soc.) Microbiol. Ecol. 43:359-366.

Mazars, G.-R., Moyret, C., Jeanteur, P., and Theillet, C.-G. 1991. Direct sequencing by thermal asymmetric PCR. Nucleic Acids Res. 19:4783.

Michielse, C. B., Hooykaas, P. J. J., van den Hondel, C. A. M. J. J., and Ram, A. F. J. 2005. Agrobacterium-mediated transformation as a tool for functional genomics in fungi. Curr. Genet. 48:1-17.

Mingot J. M., Tilburn, J., Díez, E., Bignell, E., Orejas, M., Widdick, D. A.,
Sarkar, S., Brown, C. V., Caddick, M. X., Espeso, E. A., Arst, H. N., Jr., and Peñalva, M. Á. 1999. Specificity determinants of proteolytic processing of Aspergillus PacC transcription factor are remote from the processing site and processing occurs in yeast if $\mathrm{pH}$ signalling is bypassed. Mol. Cell. Biol. 19:1390-1400.

Mullins, E. D., Chen, X., Romaine, P., Raina, R., Geiser, D. M., and Kang, S. 2001. Agrobacterium-mediated transformation of Fusarium oxysporum: An efficient tool for insertional mutagenesis and gene transfer. Phytopathology 91:173-180.

Negrete-Urtasun, S., Reiter, W., Díez, E., Denison, S. H., Tilburn, J., Espeso, E. A., Peñalva, M. Á., and Arst, H. N., Jr. 1999. Ambient pH signal transduction in Aspergillus: Completion of gene characterization. Mol. Microbiol. 33:994-1003.

Ogrydziak, D. M., and Mortimer, R. K. 1977. Genetics of extracellular protease production in Saccharomycopsis lipolytica. Genetics 87:621632.

Orejas, M., Espeso, E. A., Tilburn, J., Sarkar, S., Arst, H. N., Jr., and Peñalva, M. Á. 1995. Activation of the Aspergillus PacC transcription factor in response to alkaline ambient $\mathrm{pH}$ requires proteolysis of the carboxy-terminal moiety. Genes Dev. 9:1622-1632.

Pavletich, N. P., and Pabo, C. O. 1991. Zinc finger-DNA recognition: Crystal structure of a Zif268-DNA complex at 2.1 A. Science 252:809817.

Peñalva, M. A., and Arst, H. N., Jr. 2002. Regulation of gene expression by ambient $\mathrm{pH}$ in filamentous fungi and yeasts. Microbiol. Mol. Biol. Rev. 66:426-446.

Peñalva, M. A., and Arst, H. N., Jr. 2004. Recent advances in the characterization of ambient $\mathrm{pH}$ regulation of gene expression in filamentous fungi and yeasts. Annu. Rev. Microbiol. 58:425-451.

Peres, N. A., Timmer, L. W., Adaskaveg, J. E., and Correll, J. C. 2005. Lifestyles of Colletotrichum acutatum. Plant Dis. 89:784-796.

Poussereau, N., Creton, S., Billon-Grand, G., Rascle, C., and Fevre, M. 2001. Regulation of acpl, encoding a non-aspartyl acidprotease expressed during pathogenesis of Sclerotinia sclerotiorum. Microbiology 14:717726.

Prusky, D., McEvoy, J. L., Leverentz, B., and Conway, W. S. 2001. Local modulation of host $\mathrm{pH}$ by Colletotrichum species as a mechanism to increase virulence. Mol. Plant-Microbe Interact. 14:1105-1113.

Ramón, A. M., Porta, A., and Fonzi, W. A. 1999. Effect of environmental $\mathrm{pH}$ on morphological development of Candida albicans is mediated via the PacC-related transcription factor encoded by PRR2. J. Bacteriol. 181:7524-7530.

Rollins, J. A. 2003. The Sclerotinia sclerotiorum pac1 gene is required for sclerotial development and virulence. Mol. Plant-Microbe Interact. 16:785-795.

Schmitt, E. K., Kempken, R., and Kück, U. 2001. Functional analysis of promoter sequences of cephalosporin C biosynthesis genes from Acremonium chrysogenum: Specific DNA-protein interactions and characterization of the transcription factor PACC. Mol. Gen. Genet. 265:508-518.

Suarez, T., and Peñalva, M. A. 1996. Characterization of a Penicillium chrysogenum gene encoding a PacC transcription factor and its binding sites in the divergent $p c b A B-p c b C$ promoter of the penicillin biosynthetic cluster. Mol. Microbiol. 20:529-540.

Tilburn, J., Sarkar, S., Widdick, D. A., Espeso, E. A., Orejas, M., Mungroo, J., Peñalva, M. Á., and Arst, H. N., Jr. 1995. The Aspergillus PacC zinc finger transcription factor mediates regulation of both acid- and alkalineexpressed genes by ambient pH. EMBO (Eur. Mol. Biol. Organ.) J. 14:779-790.

Tilburn, J., Sanchez-Ferrero, J. C., Reoyo, E., Arst, H. N., Jr., and Peñalva, M. Á. 2005. Mutational analysis of the $\mathrm{pH}$ signal transduction component PalC of Aspergillus nidulans supports distant similarity to BRO1 domain family members. Genetics 171:393-401.

Timmer, L. W., Agostini, J. P., Zitko, S. E., and Zulfiqar, M. 1994. Postbloom fruit drop, an increasingly prevalent disease of citrus in the Americas. Plant Dis. 78:329-334.

Vincent, O., Rainbow, L., Tilburn, J., Arst, H. N., Jr., and Peñalva M. A. 2003. YPXL/I is a protein interaction motif recognized by Aspergillus PALA and its human homologue, AIP1/Alix. Mol. Cell. Biol. 23:16471655.

Yakoby, N., Kobiler, I., Dinoor, A., and Prusky, D. 2000. pH regulation of pectate lyase secretion modulates the attack of Colletotrichum gloeosporioides on avocado fruits. Appl. Environ. Microbiol. 66:1026-1030.

\section{AUTHOR-RECOMMENDED INTERNET RESOURCES}

Softberry, Inc. software: www.softberry.com

ExPASy Molecular Biology server: us.expasy.org

PROSITE database Motif Search webpage: motif.genome.jp/

Regulatory sequence analysis tools: http://rsat.ulb.ac.be/rsat/ 